\title{
Media Framing of News Coverage of Same-sex Marriage Surrounding the U.S. Supreme Court Legalization Decision
}

\author{
Chelsea B. Betts
}

Follow this and additional works at: https://researchrepository.wvu.edu/etd

\section{Recommended Citation}

Betts, Chelsea B., "Media Framing of News Coverage of Same-sex Marriage Surrounding the U.S. Supreme Court Legalization Decision" (2016). Graduate Theses, Dissertations, and Problem Reports. 5201. https://researchrepository.wvu.edu/etd/5201

This Thesis is protected by copyright and/or related rights. It has been brought to you by the The Research Repository @ WVU with permission from the rights-holder(s). You are free to use this Thesis in any way that is permitted by the copyright and related rights legislation that applies to your use. For other uses you must obtain permission from the rights-holder(s) directly, unless additional rights are indicated by a Creative Commons license in the record and/ or on the work itself. This Thesis has been accepted for inclusion in WVU Graduate Theses, Dissertations, and Problem Reports collection by an authorized administrator of The Research Repository @ WVU. For more information, please contact researchrepository@mail.wvu.edu. 
Media Framing of News Coverage of Same-sex Marriage Surrounding the U.S. Supreme Court Legalization Decision

\title{
Chelsea B. Betts
}

\author{
A Thesis Submitted to the \\ Reed College of Media \\ at West Virginia University \\ in partial fulfillment of the requirements \\ for the degree of \\ Master of Science \\ in \\ Journalism
}

Rita F. Colistra, Ph.D., Chair

Bob Britten, Ph. D

Catherine Mezera, M.S.

Elizabeth Cohen, Ph.D.

Reed College of Media

Morgantown, West Virginia

2016

Keywords: same-sex marriage, content analysis, framing, gay marriage, U.S. Supreme

Court legalization of marriage equality

Copyright 2016 Chelsea Betts 


\section{ABSTRACT \\ Media Framing of News Coverage of Same-sex Marriage Surrounding the U.S. Supreme Court Legalization Decision}

\section{Chelsea Betts}

The purpose of this research is to explore which frames, dominant frames, and tones are used in news coverage of same-sex marriage before and after the U.S. Supreme Court decision to legalize these marriages. In addition, public opinion surrounding the decision and agenda-setting effects were also examined. This study used a content analysis and secondary survey data from the Pew Research Center to explore these factors. A content analysis of print newspaper articles and broadcast transcripts from four print sources and six broadcast outlets was used to gather the 286-article sample. Findings suggest that the tone of the article is impacted by the type of frame that is used, (1) political/legal, (2) religion/morality, (3) civil rights/equality. Findings also suggest that religion/morality framing is the most negative in tone, followed by political/legal framing, and civil rights/equality framing is the most positive in tone. These types of frames used were also examined in the time period before and after and results indicated that political/legal framing was used more in the time before the decision, while civil rights/equality framing was used more often after the decision. The information gathered in this research will help improve understanding of the impacts of framing surrounding a landmark event and how these frames and tone of coverage may influence public opinion of same-sex marriage and its legalization. 


\section{TABLE OF CONTENTS}

1. Introduction 1

2. Literature Review 5

$\begin{array}{ll}\text { Framing } & 5\end{array}$

$\begin{array}{ll}\text { Agenda Setting } & 7\end{array}$

$\begin{array}{ll}\text { Secondary Survey Data } & 9\end{array}$

$\begin{array}{ll}\text { Politics and Same-Sex Marriage } & 10\end{array}$

$\begin{array}{ll}\text { Equality/Tolerance \& Civil Rights Framing } & 14\end{array}$

$\begin{array}{ll}\text { Religion/Morality Framing } & 15\end{array}$

Issue Specific Frames and Local vs. National Agenda Setting 18

$\begin{array}{ll}\text { Examining Frames Between Different Media } & 21\end{array}$

3. Summary of RQs \& Hypotheses 21-22

4. Method 23

5. Results 36

6. Discussion $\quad 50$

$\begin{array}{ll}\text { 7. References } & 67\end{array}$

8. Appendix A: Codebook/Training Manual 71

9. Appendix B: Newspaper Coding Sheet 76

10. Appendix C: Broadcast Coding Sheet 77 


\section{CHAPTER 1: INTRODUCTION}

Same-sex marriage and the decision about whether to legalize it has been a topic of political debate in the United States for more than 40 years. From the first gay couple to apply for a marriage license in 1970, to President Clinton's signing of the Defense of Marriage Act in 1996 and to Vermont's progressive move that allowed same-sex unions in 2000, the timeline of same-sex marriage in the U.S. has been an eventful one (Hester \& Gibson, 2007). Politics, religion, equality, economics, and legal aspects play an important role in shaping which side of the debate Americans support. As a result, the opinions an individual forms based on these related attributes can influence whether or not someone strongly supports or strongly opposes same-sex marriage (Whitehead, 2014; Baunach 2011).

Although the debate of same-sex marriage is primarily considered a topic of political policy, the news media also have played an important role in this ongoing battle between those who demand equality and those who believe same-sex marriage is an issue of morality. The gay-marriage debate became a major topic in the media in the 1990s, when three gay couples decided to challenge the marriage laws in Hawaii (Li \& Liu, 2010).

Since that first nationally publicized story concerning same-sex marriage, there have been numerous reports related to the issue of marriage and other same-sex relations that have made both local and national news ("Same-Sex Marriage, Civil Unions, and Domestic Partnerships," n.d.). Some examples include Rita Hauser, the United States Representative to the United Nations Human Rights Commission, who stated laws 
banning same-sex marriage were unconstitutional in 1970 (Nardi, 1996); the proposed ordinance supported by San Francisco's large homosexual community that would allow partners living together to be covered by the city's insurance programs in 1982 (Turner, 1982); and the arrest of six students at the University of California in 1990 who protested the Chancellor's refusal to allow gay and lesbian couples to live in family dorms, which also made the local and national news agenda (Kirka, 1990). Over the years, strong opposing opinions of same-sex marriage have influenced the number news stories published about the issue. Thus, media have played a major role in this public debate. According to Li and Liu (2010), media coverage of same-sex marriage can "set the public agenda" because it is a national issue that can lead to further discussion online, on television, and even in political debates, which can, in turn, influence people's decisions in an election (p. 73).

In addition to possible media influence on public opinion, research has shown that news stories related to same-sex marriage have resulted in a shift in public opinion over time. A content analysis conducted by Hackl, Boyer, and Galupo (2013) compared the language of more than 2,000 articles used by The New York Times to discuss same-sex marriage in 2004 and then again in 2012. The study found that in 2004, the sexualorientation label "gay" was predominantly used when referring to marriage, couples, and individuals. Eight years later, however, the results showed that the language used by The New York Times was much more inclusive with the label "same-sex" used as the most common modifier when talking about marriage, couples, and individuals (p. 521).

Trends in attitudes toward gay-marriage also have been analyzed using data from the General Social Survey. Baunach’s (2011) analysis of survey data from 1988 to 2006 
showed that attitudes changed significantly over time, with $71 \%$ opposed to gay marriage in 1988 but just $52 \%$ opposed to the idea in 2006 . She concluded that "...use of the 'equality/tolerance' framing of gay marriage by its supporters and other societal events or 'moments' may have convinced some people who used to disapprove of gay marriage in 1988 to approve of it by 2006” (Baunach, 2011, p. 346).

On June 26,2015 , the battle for legalization of same-sex marriage finally came to an end with a 5-4 Supreme Court ruling in favor of allowing same-sex couples to marry nationwide. Before the decision of this landmark case was announced, there were still 13 states in the U.S. that did not allow same-sex marriages (Zorthian, 2015).

The impacts of the decision to legalize same-sex marriage extend much further than simply allowing gay couples to wed. From an economic standpoint, same-sex couples will now receive the same financial benefits as heterosexual couples. According to a report by U.S. News online, now that same-sex marriage is legal, these couples are eligible for spousal benefits from social security; estate planning is much easier; and filing a state tax return as married and a federal tax return as an individual is a thing of the past (Taylor, 2015). Additionally, with same-sex marriage legal in every state, samesex couples also are able to legally divorce. Before the Supreme Court ruling, couples that decided to split did not have legal rights to division of property like heterosexual couples (Taylor, 2015).

This study examines the tone of coverage and frames used in news surrounding the issue of same-sex marriage before and after the U.S. Supreme Court decision to legalize it. Specifically, it asks how and how often these stories are covered and what type of language and tone (positive or negative) are associated with the topic. This study 
also considers how these frames of coverage relate to public opinion about the issue, using secondary survey data. In addition, this research explores the differences between the frames and tone of coverage used by newspaper and broadcast media sources. The current study is important and different from previous research surrounding same-sex marriage, as it seeks to explore the frames surrounding same-sex marriage after a landmark U.S. Supreme Court decision. This decision impacts the lives of not only samesex couples, but all Americans; therefore, it is important to analyze the impacts of this decision and the role played by the media in informing the public. 


\section{CHAPTER 2: LITERATURE REVIEW}

Although same-sex marriage in the United States has been officially deemed legal by the U.S. Supreme Court, the discussion about this controversial topic among the public and the news media is far from over. Throughout the more than 40 -year battle for marriage equality, the framing of same-sex marriage news has consisted of three major and recurring frames. These major frames are: the political aspect of the legalization of same-sex marriage (Warren \& Bloch, 2014), religion and morality framing (Olson, Cadge \& Harrison, 2006), and equality/civil rights or "tolerance" framing (Johnson, 2012). The following sections will outline each of these frames in news coverage related to same-sex marriage; however, first framing and agenda setting, the theoretical lenses through which the current research is discussed.

\section{Framing}

Framing was originally proposed with a sociological foundation by Goffman in 1974. Goffman (1974) explained that framing, or framing analysis, is an interpersonal theory that allows individuals to "appreciate something of their bearing on our overall understanding of the workings of the world" (p. 28). In other words, framing is how people make sense of the world around them. Later, as the theory evolved, researchers found that the way an issue is framed in the news can have a strong influence on the way that it is perceived (Scheufele \& Tewksbury, 2007). This influence is achieved by the media's selection and emphasis on a certain aspect of a topic.

Scholars have found both positive and negative aspects to media framing. According to Entman (2007), framing is often used by journalists and can be defined as 
"the process of culling a few elements of perceived reality and assembling a narrative that highlights connections among them to promote a particular interpretation" (p.164). Media coverage of controversial topics are often framed using "different angles and perspectives" (Li \& Liu, 2010, p.73.) As a result, different frames can lead to differing interpretations of the issue by an audience. This interpretation can be negative if media do not present fair and balanced coverage. Further, Li and Liu (2010) argue that biased or one-sided coverage can affect the public's trust of media and of journalists. On the other hand, framing also has been characterized as the "central organizing ideas" or principles that provide structure to news stories and help audiences make sense out of a particular issue (Gamson, 2000; Reese, 1991). This positive aspect of framing allows the public to form its own opinion about a particular issue using the information provided to them by media.

When it comes to same-sex marriage, framing is one of the most-used theories when analyzing media coverage surrounding this issue. Previous research has covered a wide variety of news frames related to same-sex marriage and gay rights, ranging from equality and civil rights framing (Baunach 2011; Liebler et al., 2009; Johnson 2102), political framing (Boyle \& Schmierbach 2005; Sherkat et al., 2011), religious framing (Whitehead 2014; Olson et al., 2006), and framing focused around the use of sexual orientation labels like "gay" versus "same-sex" (Hackl et al., 2004). Issuespecific/episodic frames in same-sex marriage news also have been analyzed ( $\mathrm{Li} \& \mathrm{Liu}$, 2010) as well as issue-specific frames in news coverage overall (de Vreese, Peter, \& Smetko, 2011). 
The current research study aimed to expand the current knowledge of same-sex marriage research by analyzing the issue-specific frame surrounding the recent U.S. Supreme Court decision to legalize same-sex marriage. According to Time Magazine, before the U.S. Supreme Court decision, there were still 13 states that had not legalized same-sex marriage (Zorthian, 2015). Comparing the frames and tone of coverage before and after this landmark case provided an opportunity to research a currently unexplored area.

RQ1: (a) What are the most common frames presented in news coverage of same-sex marriage during the seven-month period surrounding the Supreme Court's decision to legalize it? (b) Do these frames change over time?

\section{Agenda Setting}

Agenda setting, a media effects-theory, is the ability of the news media to influence the salience of topics on the public agenda (McCombs \& Reynolds, 2002). The original agenda-setting study took place at University of North Carolina at Chapel Hill and was developed by McCombs and Shaw (McCombs \& Shaw, 1972). Based around the 1968 Presidential election, the study compared the salience of issues in the news with the public's perception of the most important election issue. This comparison allowed McCombs and Shaw to determine the degree to which the media influenced public opinion (Scheufele \& Tewksbury, 2007). McCombs and Shaw found a strong correlation $(\mathrm{r}=+.967)$ between what survey participants thought was the most important issue surrounding the 1968 Presidential election, and what local and national media reported as the most important issue (1972, p. 180-181). Agenda-setting can further be simplified in the words of Cohen who once said that the press "may not be successful much of the time 
in telling people what to think, but it is stunningly successful in telling its readers what to think about" (1963, p. 13).

In previous research related to same-sex marriage in the news, agenda-setting theory has been used to determine the importance of the issue in certain media markets. Hester and Gibson (2007) used a content analysis to examine the impacts of agenda setting for the issue of same-sex marriage in an area where the issue was both local and national. In Atlanta, the market where the issue was both local and national, the news related to same-sex marriage was found to have a stronger agenda-setting influence from local media. This finding suggests that the issue of same-sex marriage was perceived as being more important in Atlanta, where the issue was both local and national, than in Chicago, where the issue was covered only on a national level. Thus, the results indicated "agenda-setting influences of local and national media are very different, with local media exerting a stronger agenda-setting influence when the issue is both local and national" (Hester \& Gibson, 2007, p. 299).

Similarly, Lee and Hicks (2011) used a survey of more than 5,000 Americans to compare their attitudes of same-sex marriage and media consumption. The study examined the role that mass media and the amount of media consumed by an audience plays in views of same-sex marriage (Lee \& Hicks, 2011). The study found that the amount and type of media consumed play an important role in public opinion and attitudes of same-sex marriage. Agenda-setting theory played an important role in the current research study, as not only the tone and frames of coverage are examined before and after the U.S. Supreme Court decision, but the amount of coverage as well. 
Secondary survey data also was used in the current research study to gauge public opinion of same-sex marriage during the time leading up to and immediately after the Supreme Court decision to legalize it. More information about this secondary survey data can be found in the Method Chapter.

\section{Public Opinion \& Political Support}

In 1996, when Gallup first asked whether or not marriages between same-sex couples should be legalized, a mere $27 \%$ of respondents said yes, while $68 \%$ of Americans were opposed to the idea. In contrast, a poll published by Gallup from May 2015, results indicated that a record high $60 \%$ of Americans support same-sex marriage (McCarthy, 2015). That number is up five percentage points from 2014, and suggests that times and opinions about same-sex marriage are changing in the U.S.

In a study conducted by Sherkat, Powell-Williams, Maddox, and Vries (2010), survey data for the support of same-sex marriage in the U.S. was analyzed from General Social Surveys from 1988-2008. The results indicated that support for same-sex marriage had increased dramatically over the 20 -year period. In 1988 , fewer than $12 \%$ of Americans "approved" or "strongly approved" of marital rights for same-sex couples. The 2008 General Social Survey data suggested that more than $39 \%$ of respondents approved or strongly approved of marriage for same-sex couples. This finding suggests that positive framing may influence public opinion over time.

In addition to changing public opinion, the same 2015 Gallup Poll also found that support for same-sex marriage has reached a new high in all political parties. The poll found that $76 \%$ of Democrats, $64 \%$ of Independents, and 37\% of Republicans support legalization (McCarthy, 2015). Support for legalization among the Republican Party has 
consistently been the lowest; however, from the 1996 Gallup Poll to the research company's most-recent poll, support from the Republican party has increased by 21 percentage points.

Increases in political support of same-sex marriage may be attributed to attempts by politicians to appeal to the voting public. With increased support from the American public, same-sex marriage may be a factor used by voters to decide whom they will elect as their next government official. According to Boyle \& Schmierbach (2005), "political rationale for same-sex marriage focuses on the consequences of supporting or opposing the practice for electoral success" (p. 5). Therefore, in order to keep up with changing public opinions of same-sex marriage, political support for same-sex marriage also may be influenced.

\section{Politics, Legality, and Same-Sex Marriage}

Since the beginning of the same-sex marriage legalization battle, politics have been at the forefront of the debate. According to Whitehead (2014), political views and opinions are strongly associated with an individual's attitudes toward same-sex marriage. On both the state and national level, politics have either inhibited or facilitated the progress of marriage equality in America. As a result, much of the news coverage concerning this issue uses political framing or political themes.

Boyle and Schmierbach (2005) analyzed 145 articles from 12 different daily newspapers to find out what portion of news coverage in 2003 focused on political reasons and actions related to same-sex marriage after the U.S. Supreme Court ruled that laws against gay sex were a form of discrimination. The results indicated that the media 
focused heavily on the political aspects of same-sex marriage, with nearly $40 \%$ of stories including either a political reason or political-action frame.

Vreese, Peter, and Semetko (2001) examined the framing politics at the launch of the euro in a cross-national comparative study of news frames. The analysis of 97 broadcast news stories from two of the most-watched evening news programs in four European countries found that roughly half of television news time was devoted to political and economic topics, and reporters were likely to emphasize conflict when covering political or economic news. The findings from Vreese, Peter, and Semetko's study also may relate to coverage of same-sex marriage. Political and economic frames are often used when covering news related to same-sex marriage; therefore, reporters may be more likely to emphasize conflict related to this issue. With a strong focus on the controversial aspects surrounding same-sex marriage in the news, media frames and tone may be more likely to influence audience perception toward opposition or support. Thus, the following research question was formed.

RQ2: Is there a relationship between tone of coverage and public opinion of same-sex marriage both before and after the Supreme Court decision?

In contrast, Liebler, Schwarts, and Harper's (2009) study de-emphasized the importance and use of conflict. They found that the media report gay-rights issues and same-sex marriage issues in “ways that don't challenge hegemonic notions of gender and sexuality, and by employing frames that privilege heterosexuality" (p. 656). They argue that this is achieved by choosing sources that are "comfortable" and by steering clear of sources that may be "controversial;" using the idea that people within the LGBT community and heterosexuals are the same; and avoiding the political aspects of same- 
sex marriage (p. 656). Similarly, Jowett and Peel (2010) also recognized that by portraying homosexual and heterosexual individuals as the same, "heteronormative couple ideologies" are maintained and the opportunity for discussion of other types of relationships decrease (p. 212). Therefore, these two studies looked at the way media downplayed the differences between heterosexual and homosexual relationships, as opposed to emphasizing conflict.

Support and opposition of same-sex marriage by key political figures has played an important role in the evolution of same-sex marriage laws in the United States. On September 21, 1996, President Bill Clinton signed a federal law that allowed states to refuse to recognize same-sex marriages performed in other states. This law, known as the Defense of Marriage Act, defined marriage as the union of one man and one woman (Baker, 2013).

Clinton was not the only president to oppose same-sex marriage. In 2004, President George W. Bush announced that he would support an amendment to the U.S. Constitution that banned gay marriage. In that same year, 11 states created constitutional amendments that restricted the marriage rights of same-sex couples. This increase in political involvement surrounding same-sex marriage also meant increased media coverage surrounding the controversial topic and a difference in tone, depending on the source. Pan, Meng, and Zhou's (2010) content analysis investigated the ideological framing in news coverage of same-sex marriage by two large-scale newspapers: The New York Times and the Chicago Tribune. The study found that since the 2000 Presidential campaign in the United States, news stories about whether or not gay and lesbian couples should have the same rights as heterosexual couples reached an all-time high. In addition, 
the results suggested that The New York Times was likely to emphasize equality in stories related to same-sex marriage, while the Chicago Tribune focused on human morality more often in relation to the topic. The use of the equality frame and the equality argument are supported by those in favor of same-sex marriage (Baunach, 2011). Further, Pan, Meng \& Zhou found that The New York Times articles covering same-sex marriage used a more positive tone (2010, p. 641.) In contrast, the morality frame used more frequently by the Chicago Tribune, is associated with opposition to same-sex marriage, and resulted in a more negative tone of coverage when used in articles related to samesex marriage (2010, p. 641).

Fast forward 11 years later and not only has the United States Supreme Court ruled same-sex marriage legal in all 50 states, but the Commander in Chief is a supporter of these unions. According to an article by The Washington Post, when President Obama endorsed same-sex marriage in 2012, he became the first U.S. President to do so (Nakamura, 2015). Additionally, after the Supreme Court decision was announced, President Obama held a press conference in response to the ruling. He stated that with this landmark decision, the U.S. Supreme Court had "made our union a little more perfect" (Nakaruma, 2015, para. 1). The President also took to social media to announce his support of legalization of same-sex marriage by using the hashtag \#LoveWins in a tweet from his personal Twitter account (para. 6). Although attitudes toward same-sex marriage have become more positive in the political world over time, support for samesex marriage by politicians is far less positive than of those who embrace the equality frame or argument. 


\section{Equality and Civil Rights Framing}

For those who support same-sex marriage, equality and civil rights are often the main focus of the discussion. These equality frames are also sometimes used when the media cover stories about same-sex marriage. According to Warren and Bloch (2014), the equality frame became popular during the 1980s and 1990s when the topic of same-sex marriage began to play a large role in politics. A 2014 study by Warren and Bloch utilized a content-analysis approach from three different newspapers and found that "same-sex marriage as a civil rights issue" was the most dominant frame of the 546 documents (articles, editorials, and letters to the editor) analyzed from The New York Times, Washington Post, and San Francisco Chronicle (p. 506).

In addition, Baunach's (2011) study analyzed secondary survey data from the General Social Survey and found that the use of equality or civil rights frames might have convinced some individuals who disapproved of gay marriage in 1988 to approve of it by 2006 (p. 346). The current study also will use secondary survey data during the time of the landmark decision to legalize same-sex marriage. This information will be used to analyze public opinion and compare the attitudes of same-sex marriage to news stories published before and after the decision.

Another content analysis study by Johnson (2012) indicated that the use of equality frames can drive opposition to same-sex marriage downward by affecting public opinion (p. 1056). In contrast, Liebler, Schwartz, and Harper's (2009) study suggests that news articles with a focus on the legal authority involved with same-sex marriage were likely to be consistent with the discrimination frame because marriage is "considered a civil right in terms of legal benefits" (p. 668). 
Given the previous literature regarding the political/legal frame and the civil rights/equality frame, the following hypothesis was formed.

H1: News stories covering the legalization of same-sex marriage using a political/legal frame will be more negatively framed than stories using a civil rights/equality frame.

\section{Religion, Morality, and Same-Sex Marriage}

Other studies have found that an individual's religion has a direct effect on whether that person supports or opposes the idea of same-sex marriage. Whitehead's (2014) study compared results from a 2010 Baylor Religion Survey to his own survey that asked for the opinions about the origins and controllability of homosexuality. The results indicated that "socially embedded" religious beliefs about homosexuality influence the support, or lack thereof, for same-sex unions (p. 716). Furthermore, the study indicated that religious beliefs could influence an individual's attribution beliefs, which can, in turn, influence the way they feel about same-sex marriage.

Similarly, Sherkat, Powell-Williams, Maddox, and Vries (2011) emphasized that conservative religious groups played a major role in the Congressional passage of the 1996 Defense of Marriage Act and other state-level prohibitions of same-sex marriage. This study analyzed data from the 1988 to the 2004-2008 General Social Surveys to find trends and indicators of support for same-sex marriage. The results indicated that church attendance, also known as religiosity, had a significant negative effect on support for same-sex marriage. In other words, those who attended church more often were less likely to support same-sex marriage.

Other studies related to religion and opinions of same-sex marriage have explored not only whether an individual is religious, but also which religious denominations are likely to support and oppose these marriages. Results from these studies found that Non- 
Protestants, Jews, and those unaffiliated with a religion are much more likely to support gay marriage (Olson, Cadge \& Harrison, 2006; Sherkat, Powell-Williams, Maddox \& Vries, 2011). Additionally, Catholics have become much more tolerant of same-sex marriage within the last 20 years, specifically Catholics who do not practice regularly (Sherkat, Powell-Williams, Maddox \& Vries, 2011).

In addition, morality framing and the use of the morality argument in opposition to same-sex marriage are often used by those who identify with a religion (Baunach, 2011). Religion and morality frames are often used together because traditional moral values are often a large focus of religion. In addition, those who disagree with same-sex marriage are often religious and base their arguments on moral reasoning (Baunach, 2011).

Olson, Cadge, and Harrison (2006) analyzed survey data from a sample of 1,610 participants from March 16-April 4, 2004, which was one month after media attention was focused on same-sex marriages being performed in San Francisco. Results suggested that those who identified moral values as one of their top two concerns related to marriage equality were more likely to oppose same-sex marriage. In addition, news stories related to same-sex marriage that used a morality frame or mentioned morality in opposition to the legalization of same-sex marriage define the institution as "sacred" and something that is between a man and a woman (Liebler, Schwartz \& Harper, 2009, p. 668). Further, Warren and Bloch (2014) note "activists opposing same-sex marriage suggest that legalization would threaten the institution of marriage and harm children" ( $p$. 505). This argument is commonly used in conjunction with the religion and the morality frame. Pan, Meng, and Zhou (2010) also mention the opposition of same-sex marriage 
and the idea that allowing gay couples to marry would take away from the religious institutions of traditional marriage and family. Thus, news stories concerning same-sex marriage with a morality or religious frame tend to be more negative in tone. Taking into consideration the overall negative opinions of same-sex marriage demonstrated by those who closely follow religion and the impact of morality framing, the following hypotheses were formed.

H2a: News stories covering the legalization of same-sex marriage using a religion/morality frame will be more negatively framed than stories using a political/legal frame.

H2b: News stories covering the legalization of same-sex marriage using a religion/morality frame will be more negatively framed than stories using a civil rights/equality frame.

Story frames are not the only way media create the overall tone of opposition or support in a news article. According to Boyle and Schmierbach (2005), sources or "actors" featured in a news story can also contribute to the overall tone of coverage. These actors can either be supporters or opponents of gay marriage and oftentimes include mainstream and powerful influencers, such as politicians (Boyle \& Schmierbach, 2005). Their 2005 study analyzed 145 news articles from 2003 and focused on the manner in which coverage was depicted when politics were involved. They found that citizens directly affected by the laws of same-sex marriage were rarely used for interviews or sources in news stories related to this controversial topic.

In 2005, religious leaders were used as sources in news stories related to same-sex marriage more frequently, with the message most likely being related to morality (Liebler et al., 2009). With that said, Brewer's (2002) study on the effects of different frames found that those who were exposed to the morality frame in gay coverage were more 
likely to talk about their opinion on gay rights in terms of morality. Thus, sources used for comments and remarks in stories related to same-sex marriage may influence tone of coverage related to this issue.

\section{Issue Specific Frames and Local vs. National Agenda Setting}

Previous research of framing in the news media has found that frames of a specific topic are often focused around a specific current event related to that topic According to de Vreese, Peter, and Semetko (2001), "Issue-specific frames pertain to specific topics or news events, whereas generic frames are broadly applicable to a range of different topics...”(p.108). Their 2001 content analysis study centered around the frames used in the launch of the Euro and suggested news coverage of the launch was entirely event driven or "issue specific." In other words, most news about the Euro pertained specifically to the upcoming launch. Additionally, results indicated that news coverage disappeared almost entirely after the currency was officially released and in circulation (de Vreese, Peter \& Smetko, 2001, p. 115).

Issue-specific frames can be compared to episodic frames which were originally studied by Iyengar (1990) in his survey, which aimed to determine how people thought about poverty based on the frames used in the media. Iyengar studied the episodic frame alongside the thematic frame, and described thematic frames as news consisting of general information. Some examples he used to illustrate thematic frames in terms of poverty were the poverty rate, number of states showing increases in hunger, or changes in the government's definition of poverty (Iyengar, 1990). In contrast, the episodic frame was described by Iyengar (1990) as a story "covered in terms of personal experience; the viewer is provided with a particular instance of an individual" or group that is affected by 
the issue at hand (p. 22). To further explore the use of episodic and issue-specific framing in regards to the current study, the following hypothesis was formed.

H3: Issue specific or episodic framing will be used more often in news stories leading up to the time of the U.S. Supreme Court decision than after the decision.

The idea of event-driven media framing has been utilized before in the case of same-sex marriage. Some of these various cultural events include the HIV/AIDS pandemic, the presidential elections in 2000 and 2004, and certain court cases related to same-sex marriage like the Defense of Marriage Act and the passage of Don't Ask Don't Tell (Baunach, 2011, p. 349). For the current study, the "issue specific" or "episodic" frame being analyzed is the U.S. Supreme Court's decision to pass the law allowing same-sex couples to marry.

Other studies have used the timing of current events to gather a sample of news articles that will provide them with enough information to study other media related issues. Li and Liu's (2010) content analysis examined fairness and balance of coverage in U.S. newspapers after the Mayor of San Francisco agreed to issue marriage licenses to same-sex couples. This study aimed to discover whether the news coverage of same-sex marriage was fair and balanced after a major current event related to the issue took place. Overall, the study found that coverage of same-sex marriage after this event was fair and balanced and according to the researchers, the results "suggest that the importance of a topic, public involvement, and national implication of a controversial issue are factors affecting fairness and balance of coverage and prompt journalists to exert more efforts to produce fair and balanced coverage" (p. 86). Based upon this finding, the current study proposes the following hypothesis.

H4: News stories after the Supreme Court decision will be more balanced/neutral than those before the decision. 
This idea of news story framing related to current events can also be traced back to the first appearance of same-sex marriage in the news when gay couples in Hawaii challenged the marriage laws there in the 1990s (Li \& Lui, 2010, p. 72). Warren and Bloch's (2014) content analysis also used a current event in the news to examine the tone of media coverage of same-sex marriage during different periods of time. California's Proposition 8 "sought to amend California's state constitution to define the parameters of legal marriage as those solely between males and females" (p. 503). This voter-initiated ballet would eliminate the definition of marriage as being between a man and a woman, allowing same-sex couples to marry in the state. Warren and Bloch compared frames of Proposition 8 in three newspapers: The San Francisco Chronicle, The New York Times, and The Washington Post. This method allowed researchers to compare frames used in national newspapers to frames used in a newspaper local to California over a period of time (May 2008-August 2010) when Proposition 8 received a significant amount of media coverage.

In event related news coverage, need for orientation also plays a role in an individuals' knowledge and interest in the subject at hand. According to McCombs \& Reynolds (2002), an individual's need for orientation is determined by the relevance of the topic to the person and how familiar they are with that particular topic. Further, McCombs and Shaw (1974) note that if an issue pertains to an individual or may affect them and they do not have full knowledge of the topic, they will have a high need for orientation and, therefore, agenda-setting effects will be strong. 


\section{Examining Frames Between Different Media}

Previous research related to media presentation of same-sex marriage has been analyzed with content analyses mainly consisting of newspaper articles; however, a 2013 Gallup Poll found that only about 9\% of Americans get their news from newspapers and other print publications (Saad, 2013). There are few research studies that use broadcast news as a source of analysis in same-sex marriage research. Additionally, according to that same Gallup Poll, 55\% of Americans watch television to obtain their news and it is the primary news source for those ages 18-29 years-old, 30-49 years-old, 50-64 years old, and those ages 65 years or older (Saad, 2013). With these statistics in mind, the current research study will expand on previous research by analyzing news related to same-sex marriage in both broadcast and print news sources.

RQ3: Does (a) frame (b) amount of coverage, and (c) tone of coverage differ between media type (newspaper and broadcast)?

\section{Summary of Research Questions and Hypotheses}

In summary, the current research study used the previously mentioned research questions and hypotheses to expand the knowledge and literature of same-sex marriage research in relation to the media. The research questions and hypotheses that were examined are listed below in the order in which they appear within the literature review.

RQ1: (a) What are the most common frames presented in news coverage of same-sex marriage during the four-month period surrounding the Supreme Court's decision to legalize it? (b) How do these frames change over time? 
RQ2: Is there a relationship between tone of coverage and public opinion of same-sex marriage both before and after the Supreme Court decision?

H1: News stories covering the legalization of same-sex marriage using a political/legal frame will be more negative in tone than stories using a civil rights/equality frame.

H2a: News stories covering the legalization of same-sex marriage using a religion/morality frame will be more negative in tone than stories using a political/legal frame.

H2b: News stories covering the legalization of same-sex marriage using a religion/morality frame will be more negative in tone than stories using a civil rights/equality frame.

H3: Issue specific or episodic framing will be used more often in news stories leading up to the time of the U.S. Supreme Court decision than after the decision.

H4: News stories after the Supreme Court decision will be more balanced/neutral than those before the decision.

RQ3: Does (a) frame (b) amount of coverage, and (c) tone of coverage differ between media type (newspaper and broadcast)? 


\section{CHAPTER 3: METHOD}

This study examined the frames used and tone of coverage of same-sex marriage news before and after the U.S. Supreme Court decision to legalize it using a content analysis of newspaper and broadcast sources. More specifically, the current study analyzed articles from newspapers and transcripts from broadcast sources for frame, dominant frame, thematic or episodic frame, tone, and amount of coverage, from the LexisNexis Academic database. The sampling process as well as operationalization of variables are discussed in the paragraphs that follow.

\section{Time frame}

Although previous research has explored the perceptions and opinions of samesex marriage throughout the years, there was little to no research on the opinions of samesex marriage after the U.S. Supreme Court's decision to legalize it. In addition, previous research also had explored the frames and tone of coverage used by media when covering stories related to same-sex marriage; however, no research study had explored the difference in tone of coverage before or after this major decision. According to Winter and Eyal (1981), four-to-six weeks is the ideal amount of time to analyze news coverage in an agenda-setting study. In addition, Camaj and Weaver (2013) looked at U.S. election campaign coverage ranging from one to three months prior to the administration of a public opinion survey in their content analysis.

The current study used a three-month time period before the decision because this time frame was consistent with previous content analysis studies. In addition, this time frame allowed for comparison of secondary survey data related to same-sex marriage and the tone of coverage related to this issue. To examine potential changes over time, 
newspaper articles and broadcast transcripts related to same-sex marriage also were analyzed two months after the U.S. Supreme Court decision beginning on June 27, 2015, the day after the decision. A three-month time period after the decision was considered; however, after collecting the sample of newspaper articles for analysis, the third month after the decision (September 2015) was found to consist mainly of stories surrounding the Kim Davis marriage- license-scandal. As a result, articles and broadcast transcripts for the month of September were excluded so the frames surrounding the topic under study, rather than the Kim Davis marriage-license-scandal would be the sole focus.

\section{Selection of Sample}

The sample of news articles and broadcast transcripts selected for this content analysis study were found with the Lexis-Nexis Academic database using the search terms "same-sex marriage," "gay marriage," "civil unions," "marriage equality," "marriage AND homosexual," "gay AND rights," and "marriage AND defense." Similar search terms were used by the Pew Research Center in their content analysis of same-sex marriage (Pew Research Center, n.d.). In addition, the terms "NOT op-ed" and "NOT opinion" and "NOT editorial" were also used to filter out any opinion articles related to the issue of same-sex marriage. Excluding opinion and op-ed pieces allowed for analysis of strictly journalistic reporting related to this controversial issue, as news coverage is the focus of the current study.

Newspapers for the study were comprised of top-circulation newspapers that were represented in the Lexis-Nexis Academic database. According to a ranked list of the top25 U.S. newspapers by Alliance for Audited Media in 2013, the top five U.S. newspapers by circulation are The Wall Street Journal, The New York Times, USA Today, The Los 
Angeles Times, and New York Daily News (Alliance for Audited Media, 2013).

Examining articles from the top-circulation U.S. newspapers allowed for a content analysis of stories related to same-sex marriage that had likely been read by the largest number of people. Further, examining articles that had been viewed by a large group of individuals allowed for deeper understanding of the potential influences of framing and agenda setting as it related to this particular issue.

Articles from The Wall Street Journal were not analyzed in the current study because they were not available on the Lexis-Nexis Academic database. In place of The Wall Street Journal, the current study analyzed articles from The Washington Post. The Los Angeles Times was also excluded because an initial article search yielded zero articles for this newspaper. In addition, the New York Daily News was replaced with the Denver Post because a newspaper from New York was already represented. The Washington Post and Denver Post were selected as replacements because they are among the top-10 circulation newspapers, and also are included in the Lexis-Nexis Academic database. Thus, the final list of newspapers to be included in the analysis was The New York Times, USA Today, The Washington Post, and Denver Post.

For the current study, broadcast transcripts also were analyzed for the three-month time period before and two-month period after the U.S. Supreme Court decision to legalize same-sex marriage. In a previous study by Hester and Gibson (2007), a LexisNexis search of broadcast transcripts also was used for their agenda-setting research of same-sex marriage. These broadcast sources included ABC, CBS, CNN, FOX, and NBC and were also used for sample selection in the current study in addition to MSNBC. 
Analysis included all news items, including feature stories, about same-sex marriage, regardless of page, section, or length of article; however, letters to the editor and opinion articles were excluded because of this study's focus on news framing. According to McKeever (2012), opinion articles should be excluded because "news framing is generally considered to be a function of reporting rather than public response" (p. 222). An initial Lexis-Nexis Academic search using the key search terms mentioned above yielded a total of 360 articles for the three-month time period before the U.S. Supreme Court decision. This initial total included searches from The New York Times (161), The Washington Post (126), USA Today (51), and the Denver Post (22). These sources provided a sample that was representative of several different areas throughout the United States.

An initial search of broadcast transcripts from before the decision yielded a total of 273 samples for content analysis. This total included CNN (116), Fox News (33), CBS (29), ABC (25), NBC (23) and MSNBC (47). An initial keyword search of news coverage concerning same-sex marriage was also conducted for the three-month time period after the decision. Newspaper coverage of same-sex marriage during the time period after the decision showed a total of about 401 articles. This total included The New York Times (170), The Washington Post (128), Denver Post (59), and USA Today (44). Broadcast transcript totals for the time period after the decision yielded a total of 482 transcripts. These totals included CNN (225), Fox News (45), CBS (73), ABC (62), NBC (39) and MSNBC (38).

The initial keyword search results for newspaper and broadcast articles were narrowed to eliminate a large portion of unrelated stories before printing. After printing, 
the sample was further narrowed once the articles and transcripts could be read more thoroughly and more exclusions were made. The types of stories excluded were news briefs, international stories about same-sex marriage, stories from the magazine desk, obituaries, stories from the style desk, briefs by state (Washington Post), politicians "on the issues" (New York Times), corrections, editors notes, listings, digests, and stories that only briefly mentioned same-sex marriage without elaborating on the issue.

After the articles were inspected to ensure the previously mentioned exclusions were made, the number of articles and transcripts coded totaled 286. Of those 286 cases, 150 were newspaper articles and 136 were broadcast transcripts. There were 61 articles coded from The New York Times, 42 from The Washington Post, 19 Denver Post articles, and 27 USA Today articles. There were 17 broadcast transcripts coded from CBS, 49 from CNN, 27 from FOX, 19 from ABC, 7 from NBC and 18 from MSNBC.

The unit of analysis for this study was the complete news article or transcript. Articles and transcripts found using the Lexis-Nexis Academic database were printed for two graduate student coders to analyze. The researcher held a codebook training session with the second coder, and the coding protocol was pre-tested using articles about samesex marriage that were not used in the final analysis. Adjustments to the coding protocols were made to ensure clarity and to improve the chances for high inter-coder reliability for the sample of articles and transcripts that were used for the analysis. A complete discussion of inter-coder reliability is discussed later in this chapter. 


\section{Secondary Survey Data}

To examine public opinion related to same-sex marriage before and after the U.S. Supreme Court decision, the current study analyzed secondary survey data from the Pew Research Center. This secondary data source is described in the paragraphs that follow.

\section{Pew Research}

The survey conducted by Pew Research Center, which reached a national sample of 2,002 adults 18 years of age and older, living in all 50 states and the District of Columbia, was conducted on May 12-18, 2015, about one month before the landmark Supreme Court decision, and again on July 14-20, 2015, about one month after the decision. Of the 2,002 respondents, 700 were interviewed on a landline telephone, and 1,302 were interviewed on a cell phone.

The survey was conducted by interviewers at Princeton Data Source under the direction of Princeton Survey Research Associates International. Sampling was executed using landline and cell phone random digit dialing methods. Respondents in the landline sample were chosen by asking for the youngest adult male or female that was at least 18 years of age. A question from the survey was selected to assess how tone of coverage (from the content analysis) and public opinion (from the survey) relates to Research Question 2 of the study: Is there a relationship between tone of coverage and public opinion of same-sex marriage both before and after the Supreme Court decision? The question used from this survey to assess this relation was "Do you strongly favor, favor, oppose, or strongly oppose allowing gays and lesbians to marry legally?" Because this survey question was asked both before and after the U.S. Supreme Court decision to legalize same-sex marriage, the data collected by Pew Research Center from this question 
was analyzed to compare public opinion to the tone of news coverage related to same-sex marriage during Time 1 (before the decision) and Time 2 (after the decision) of the current study.

\section{Operationalization of Variables}

\section{Time}

For the current study, time was divided into two separate three-and two-month periods. Time 1, which was two months before the U.S. Supreme Court decision, began on April 1, 2014, and ran through June 25, 2015. Time 2 included the two months after the U.S. Supreme Court decision, which began on June 27, 2015 and ended on August 28,2016 . The date of the decision, June 26, 2015, was excluded from the content analysis because it did not fit in either time period.

\section{Amount/Length of Coverage}

The amount of coverage was determined by calculating the number of stories from each medium for both periods of time (before and after the decision). This measure allowed for an analysis of agenda-setting effects before and after the U.S. Supreme Court decision to legalize same-sex marriage. In addition, word counts of newspaper articles and broadcast transcripts were also recorded for comparison of length of coverage and the time period in which it was published or broadcasted.

\section{Frames}

Coders determined presence or absence of frames in news coverage as well as tone and the dominant frame used in each article or transcript. This research focused on three different types of frames: the religion/morality frame, the civil rights/equality frame, and the political/legal frame. An "other" frame was also added to the three main 
frames and was assessed for presence or absence. The "other" frame was used sparingly but when it was selected, coders were instructed to manually write in the frame they believed was present in the story. In addition, the use of a thematic or episodic frame was also assessed. Coders were also instructed to select all of the frames that applied for each story. Therefore, more than one frame could be present for each broadcast transcript or newspaper article. For the dominant frame category, only one frame was selected for each story. Each of the main story frames are described in the paragraphs that follow.

Religion/morality frame was defined by stories that included religious attitudes and beliefs of individuals or groups and also often mentioned traditional moral values and the sacred institution of marriage between a man and a woman as an opposition to samesex marriage (Johnson, 2012; Liebler, Schwartz, \& Harper, 2009). These two frames were combined because in a framing study by Boyle and Schmierbach (2005), morality and religion were combined and defined as making some reference to moral or religious decrees or guidelines that implied a stance on same-sex marriage.

Equality/civil rights framing was defined by strong support for same-sex marriage through the language of "equal rights" and other invocations of equality (Baunach, 2011, p. 348). In addition, this frame was defined by stories that insisted on the normality of same-sex marriages in their similarities to heterosexual marriages (Jowett \& Peel, 2010).

Political/legal framing in relation to same-sex marriage news coverage was defined by articles using political support or opposition by certain political parties or political influencers, policy changes (including the passage of new laws, constitutional bans, and the issuing of marriage licenses), and economic consequences or issues (Li \& 
Lui, 2010). Political frames also are often defined by news that deals with conflict (de Vreese, Peter \& Semetko, 2001).

The final frame category that was used is $\boldsymbol{O}$ ther, which can be defined as a news frame that does not fit into any of the previously mentioned framing categories. This frame was directed to be used sparingly, as most articles should have fallen into one of the other three categories, as evidenced in previous research.

In addition to the presence or absence of frames, coders also determined the dominant frame of each article by selecting only one of the main frames that best represented the overarching theme of the story. Dominant frame was defined using McKeever's (2012) description as “the predominant, or most frequently mentioned theme or central organizing idea within the article" (p.223).

The presence or absence of a thematic or episodic frame also was measured for each news story. Episodic and thematic frames were defined using the variable measurements from a previous study. Li and Liu's (2010) study of framing and coverage of same-sex marriage in U.S. newspapers defined episodic frames as those taking place in the form of event-oriented reports that depict public issues in terms of concrete circumstances. In addition, they defined thematic frames as being more general and placing the issue in a broader context ( $\mathrm{Li} \& \mathrm{Liu}, 2010)$. The use of either thematic or episodic frame was measured in addition to news frames used within the article and the overall dominant frame of the entire article.

\section{Tone}

Tone of coverage also was measured for each article and transcript to be coded. Tone was coded as negative, neutral, balanced, or positive for each article and was based 
on the entire article or story. Tone can be defined as the attitude of the media within a story that uses words and imagery to create a desired emotion (Studley, 2013). Using descriptions for tone from previous studies, the following definitions were formulated. Negative tone was chosen by coders if the story contained negative statements or quotes, contained words that give a sense of disapproval or disregard, accusations or unflattering comments, or words or phrases that portrayed same-sex marriage or the legalization of same-sex marriage in a negative light (e.g., see Colistra, 2010). Examples of these negative words and phrases are included in the codebook in Appendix A.

Neutral articles were defined as having neither a positive nor a negative tone and containing only factual information, and balanced articles were defined as containing an equal number of both positive and negative comments related to same-sex marriage or its legalization. Finally, positive tone was defined by stories that contained statements or quotes that portrayed same-sex marriage in a positive light and may have contained praise, approval, flattery, or optimism concerning same-sex marriage or the legalization of same-sex marriage. Examples of positive words and phrases can be found in the codebook located in Appendix A.

\section{Public Opinion}

Public opinion of same-sex marriage was gathered from secondary survey data and was not coded on the code sheet. The secondary survey data that was used came from the Pew Research Center. Initially, information collected from a Gallup Poll was also going to be analyzed for public opinion. Unfortunately, Gallup was not able to provide a data set, and a representative pointed out that there was a mistake on the date that the survey responses to be used for the current study were collected. Thus, the response was 
not within the appropriate time frame for this research, and the Gallup Poll information was omitted from the study. The secondary survey data from Pew Research Center that was used came from the question "Do you strongly favor, favor, oppose, or strongly oppose allowing gays and lesbians to marry legally?" This question was asked before the decision on May 12-18, 2015 and after the decision on July 14-20, 2015. These data were analyzed both before and after to compare public opinion of same-sex marriage to the tone of media coverage related to the issue over time. Measuring public opinion before and after the decision for the current study allowed for deeper understanding of the influences of media framing and tone as it related to public opinion of same-sex marriage.

\section{Inter-coder Reliability}

Two graduate students coded the materials in this content analysis. One student coded all 286 new stories (broadcast and print) from the sample and the other graduate student coded approximately $20 \%$ (60) of the sample after a codebook training session, as suggested by Pan, Meng \& Zhou (2010). Stratified random sampling was used to select articles and transcripts for inter-coder reliability. The articles and transcripts were divided into Time 1(before the decision) and Time 2 (after the decision) and then randomly selected in order to be representative of the study sample (McKeever, 2012). The percentage of articles to recode for reliability was based on the final sample size and on previous research recommendations.

Scott's pi (1955) was used to calculate the inter-coder reliability of tone, frames used, and dominant frame. Scott's pi was calculated for the presence or absence of each frame used in the news story. The religion/morality frame (frame 1) was coded the same by both 
coder 1 and coder 2 for all 60 sub-sample articles, resulting in 100\% agreement. For the political/legal frame (frame 2), both coders also agreed $100 \%$ of the time for the 60 article sample. The civil rights/equality frame (frame 3) showed 56 agreements and four disagreements for the 60 cases coded. As a result, percent agreement was $93 \%$ and Scott's pi was .78. The other frame showed 57 agreements and three disagreements between coder 1 and coder two. This yielded a percent agreement of $95 \%$ and a Scott's pi value of .37 .

Although percent agreement for the other frame category was high, the Scott's pi value did not reflect this high percentage. This low value was due to the more frequent selection of the other category by coder 1 but not coder 2 . In addition, according to DiStaso and Bortree (2014) 'the way Scott's pi is calculated makes it conducive to skewed values for variables that do not have a lot of variation" (p. 163). For example, in the current study, the coding categories were dichotomous, either present or absent, so there was very little variation. Therefore, it has been suggested to defer to the percent agreement (Joyce, 2013). They go on to explain that even variables with a low Scott's pi value are deemed acceptable when they have a very high coder agreement. In the current study, the two variables with the lowest Scott's pi value were the other frame (.384) and the Episodic v. Thematic frame (.658). Despite the low Scott's pi value, the other frame and the Episodic vs. Thematic frame categories had a very high percent agreement of $95 \%$ and $98.3 \%$, respectively.

Inter-coder reliability was also calculated for the dominant frame category and showed a percent agreement of $93 \%$ with 56 agreements and four disagreements between coder 1 and coder 2 . Scott's pi for this category was .87. The presence or absence of an 
episodic or thematic framed was also assessed using the Scott's pi calculation for intercoder reliability. With 59 agreements and one disagreement between coders, percent agreement was $98 \%$ and Scott's pi was .66. Story tone also was assessed for inter-coder reliability and showed 54 agreements and six disagreements between coder 1 and coder 2 . With a $90 \%$ agreement for this category, the Scott's pi calculation was .837 . Scott's pi was calculated for each category both by hand and using the online inter-coder reliability calculator ReCal2 for accuracy.

\section{Data Analysis}

Data collected from this content analysis study was analyzed using simple descriptive statistics, Chi-square tests, and independent sample t-tests to answer each research question and/or test the hypotheses. The data collected was analyzed in the most recent version of SPSS (version 23.0). The significance and strength of the relationships were assessed using chi-square tests and Cramer's V. Cramer's V values varied depending on the degrees of freedom used for the analysis and are further explained in the results. The results of these analyses are discussed in the chapter immediately following. 


\section{CHAPTER 4: RESULTS}

To examine the framing and agenda-setting effects in news coverage related to same-sex marriage before and after this landmark decision, a content analysis was conducted. A total of 286 news articles and broadcast transcripts were coded from April 1, 2015 to August 28, 2015. After running the appropriate statistical analyses for each research question and hypothesis, the results were recorded and are further explained in the sections that follow.

RQ1(a): What are the most common frames presented in news coverage of same-sex marriage during the four-month period surrounding the Supreme Court's decision to legalize it?

Research question 1(a) aimed to discover which of the four main frames within the current study (religion/morality, political legal, civil rights/equality, and other) is used most often when talking about the legalization of same-sex marriage. Descriptive statistics were used to find out what percentage of the total sample (286) was represented by each frame. The breakdown of each frame is shown in Table 1.

As previously mentioned, coders were instructed to select all frames that were present; therefore, more than one frame could be chosen for each newspaper article or broadcast transcript. Therefore, it is important to note that the percentages of each frame total more than 100 because more than one story frame could be selected as present by the coder for each news story. The political/legal frame was the most common frame used in stories about same-sex marriage surrounding the U.S. Supreme Court decision. The political/legal frame was present in $91.6 \%$ (262) of the 286 stories. The civil rights/equality frame was the second most-used frame in stories about same-sex marriage with $80.8 \%$ (231), followed by the religion/morality frame with $53.1 \%$ (152). Finally, the 
other frame was the least-common frame used in the selected sample of news coverage surrounding same-sex marriage, and was present just $10.1 \%$ (29) of the time.

Table 1: Presence of Story Frames Surrounding the U.S. Supreme Court Decision

\begin{tabular}{|l|l|}
\hline \hline Story Frame & $\%$ (count) \\
\hline \hline Political/Legal & $91.6 \%$ \\
& $(262)$ \\
\hline Religion/Morality & $53.1 \%$ \\
& $(152)$ \\
\hline Civil Rights/Equality & $80.8 \%$ \\
& $(231)$ \\
\hline Other & $10.1 \%$ \\
& $(29)$ \\
\hline Total N & 674 \\
\hline
\end{tabular}

Note: Total $\mathrm{N}$ is not equal to 286 because story more than one frame could be selected as present by the coder for each story.

Dominant frame was also examined. Only one dominant frame could be coded per story with the frame category that best represented the overarching theme of the entire newspaper article or broadcast transcript. The prevalence of each frame as the dominant story frame is shown in Table 2. The most dominant frame was the political/legal frame with $61.5 \%$ (176) of news stories coded containing this overarching frame. The second most dominant frame was the civil rights/equality frame with $17.1 \%$ (49), followed by the religion/morality frame with $16.4 \%$ (47). Thus, it is evidenced in the current study that stories discussing the political and legal aspects of the issue dominated coverage in the media. 
Table 2: Dominant Frames Used in Stories Surrounding the U.S. Supreme Court Decision

\begin{tabular}{|l|l|}
\hline \hline Story Frame & $\%$ (count) \\
\hline Political/Legal & $\begin{array}{l}61.5 \% \\
(176)\end{array}$ \\
\hline Religion/Morality & $16.4 \%$ \\
& $(47)$ \\
\hline Civil Rights/Equality & $17.1 \%$ \\
& $(49)$ \\
\hline Other & $4.9 \%$ \\
& $(14)$ \\
\hline Total \% & $100 \%$ \\
Total N & 286 \\
\hline
\end{tabular}

\section{RQ1(b): How do these frames change over time?}

In order to assess how the main story frames used changed over time in news coverage of same-sex marriage surrounding the decision, a Chi-square test was run to compare the prevalence of each dominant frame before and after the decision to legalize same-sex marriage. The results indicated that there was a significant difference in the use of the political/legal and civil rights/equality frames over the five-month period $\left(\chi^{2}(3\right.$, $286)=23.86, \mathrm{p}<.001$, Cramer's $\mathrm{V}=.289)$ with a large effect size as shown in Table 3. This finding suggests that the political/legal frame was used more in the time period before the decision when politics and legality played a role in the discussion of same-sex marriage leading up to the decision. In addition, this finding also suggests that civil/rights equality framing was used more often after the decision when the legalization of samesex marriage was no longer a question of legality. 
Table 3: Dominant Frame Use Over Time

\begin{tabular}{|l|l|l|l|}
\hline \hline Dominant Frame & $\begin{array}{l}\text { Before Decision } \\
\% \text { (count) }\end{array}$ & $\begin{array}{l}\text { After Decision } \\
\% \text { (count) }\end{array}$ & $\begin{array}{l}\text { Total } \\
\% \text { (count) }\end{array}$ \\
\hline Religion/Morality & $14.6 \%$ & $18.9 \%$ & $16.4 \%$ \\
& $(24)$ & $(23)$ & $(47)$ \\
\hline Political/Legal $^{\mathrm{a}}$ & $72.6 \%$ & $46.7 \%^{\mathrm{a}}$ & $61.5 \%$ \\
& $(119)$ & $(57)$ & $176)$ \\
\hline Civil Rights/Equality & $9.1 \%{ }^{\mathrm{a}}$ & $27.9 \%^{\mathrm{a}}$ & $17.1 \%$ \\
& $(15)$ & $(34)$ & $(49)$ \\
\hline Other & $3.7 \%$ & $6.6 \%$ & $4.9 \%$ \\
& $(6)$ & $(8)$ & $14)$ \\
\hline Total \% & $100 \%$ & $100 \%$ & $100 \%$ \\
Total N & $(164)$ & $(122)$ & $(286)$ \\
\hline
\end{tabular}

$\chi^{2}(3,286)=23.86, \mathrm{p}<.001$, Cramer's V $=.289$

${ }^{a}$ Standardized Residuals $> \pm 2$, which indicates these frames account for the significant differences.

RQ2: Is there a relationship between tone of coverage and public opinion of same-sex marriage both before and after the Supreme Court decision?

To assess the relationship between the tone of coverage in news stories related to same-sex marriage surrounding the decision, the survey question from Pew

"Do you strongly favor, favor, oppose, or strongly oppose allowing gays and lesbians to marry legally?" was used. Because this question was asked both before and after the decision, the data collected by Pew could be analyzed to compare public opinion of same-sex marriage and the tone of coverage information from the current study in both Time 1 and Time 2. There were a total of 164 newspaper articles and broadcast transcripts from the time period before the U.S. Supreme Court decision and 122 articles and transcripts from the time period after the decision. These articles were assessed for story tone (negative, neutral/balanced, or positive) and were compared to the public opinion from Pew Poll responses in a side-by-side table. After determining the number of articles for each category of tone before and after the decision, the frequencies of each response to the Pew Poll (strongly favor, favor, oppose, and strongly oppose) were also 
determined for the surveys distributed in both May (before the decision) and July (after the decision). By comparing the tone of coverage to the responses in the Pew Poll both before and after the decision, similarities or differences in the data could be acknowledged. There were five response options for Pew Poll participants to choose from. Strongly favor, favor, oppose, strongly oppose, or don't know/refuse to answer. For the analysis of this research question, the "don't know/refuse" option was excluded to examine only the opinions of those who took a definite stance on the issue.

The survey results from the Pew Poll distributed in May indicated that $30.2 \%$ (571) favored allowing gays and lesbians to marry, $29.1 \%$ (550) strongly favored these marriages, while $21 \%$ (396) strongly opposed and $19.7 \%$ (372) opposed the idea. A total of 1,889 respondents answered this question $(\mathrm{M}=2.68, \mathrm{SD}=1.11)$.

The results from the Pew Poll that was distributed in July to collect opinions of same-sex marriage after the U.S. Supreme Court decision indicated that $27.7 \%$ (555) strongly favored these types of marriages, $26.3 \%$ (526) said they favored a law that would allow gays and lesbians to marry, another 20.8\% (417) opposed, and $17.6 \%$ (352) strongly opposed allowing gays and lesbians to marry. A total of 1850 respondents answered this poll $(\mathrm{M}=2.69, \mathrm{SD}=1.09)$.

After examining the frequencies for the Pew Data collected both before and after the decision, the current study noted that $59.3 \%$ of respondents either favored $(30.2 \%)$ or strongly favored (29.1\%) allowing gays and lesbians to marry in Time 1. Additionally, $58.4 \%$ of respondents either favored (28.4\%) or strongly favored (30\%) allowing gays and lesbians to marry in Time 2. When compared to the amount news stories about same- 
sex marriage with a positive tone (Time $1=42.7 \%$, Time $2=44.3 \%$ ) there was virtually no difference or very little change in both of these variables.

Although a correlation analysis and significance test could not be run due to the nature of using two data sets with a different number of cases, ${ }^{1}$ a comparison of descriptives suggest that the tone of coverage presented in dominant media frames in the current study were reflected in the public opinion data of the Pew polls. Thus, one may argue that agenda-setting effects may have played a role in opinions of same-sex marriage before and after the decision.

Table 4: Public Opinion Compared to Story Tone Over Time

\begin{tabular}{|c|c|c|c|c|c|c|c|}
\hline \multicolumn{4}{|c|}{ Time 1} & \multicolumn{4}{|c|}{ Time 2} \\
\hline \multicolumn{2}{|c|}{ Tone } & \multicolumn{2}{|c|}{$\begin{array}{c}\text { Pew } \\
\text { Public Opinion }\end{array}$} & \multicolumn{2}{|c|}{ Tone } & \multicolumn{2}{|c|}{ Pew Public Opinion } \\
\hline Negative & $\begin{array}{l}34.8 \% \\
(57)\end{array}$ & $\begin{array}{l}\text { Strongly } \\
\text { Oppose }\end{array}$ & $\begin{array}{l}21 \% \\
(396)\end{array}$ & Negative & $\begin{array}{l}36.9 \% \\
(45)\end{array}$ & $\begin{array}{l}\text { Strongly } \\
\text { Oppose }\end{array}$ & $\begin{array}{l}19 \% \\
(352)\end{array}$ \\
\hline & & Oppose & $\begin{array}{l}19.7 \% \\
(372)\end{array}$ & & & Oppose & $\begin{array}{l}22.5 \% \\
(417)\end{array}$ \\
\hline $\begin{array}{l}\text { Neutral/ } \\
\text { Balanced }\end{array}$ & $\begin{array}{l}22.6 \% \\
(37) \\
\end{array}$ & & & $\begin{array}{l}\text { Neutral/ } \\
\text { Balanced }\end{array}$ & $\begin{array}{l}18.9 \% \\
(23)\end{array}$ & & \\
\hline Positive & $\begin{array}{l}42.7 \% \\
(70)\end{array}$ & Favor & $\begin{array}{l}30.2 \% \\
(571)\end{array}$ & Positive & $\begin{array}{l}44.3 \% \\
(54) \\
\end{array}$ & Favor & $\begin{array}{l}28.4 \% \\
(526) \\
\end{array}$ \\
\hline & & $\begin{array}{l}\text { Strongly } \\
\text { Favor }\end{array}$ & $\begin{array}{l}29.1 \% \\
(550)\end{array}$ & & & $\begin{array}{l}\text { Strongly } \\
\text { Favor }\end{array}$ & $\begin{array}{l}30 \% \\
(555)\end{array}$ \\
\hline $\mathrm{N}$ & 164 & $\mathrm{~N}$ & 1,889 & $\mathrm{~N}$ & 122 & $\mathrm{~N}$ & 1,850 \\
\hline
\end{tabular}

Total N (news stories): 286

Total N (Pew Poll responses): 3,739

Note: A correlation analysis could not be used because two different sets of data were used and although the data sets could be merged, they had a different number of cases for each of the two variables.

Therefore, it was not possible to run a direct analysis.

RQ3: Does (a) dominant frame (b) amount of coverage, and (c) tone of coverage differ between media type (print and broadcast)?

\footnotetext{
${ }^{1}$ Pew data set questions were merged into the current study data set; however, they had a different number of cases so it was not possible to run valid statistical analyses on these variables. Therefore, only the descriptives are reported for a side-by-side comparison.
} 
Research question 3 was explored to determine if the amount of coverage, the tone used, and dominant frame used in each news story significantly differed between print and broadcast news sources. Each of these variables was assessed individually using a Chi-square analysis or an independent samples t-test.

\section{RQ 3(a) Dominant frame by medium}

A Chi-square analysis was used to answer part A of research question 3 that asked whether the dominant frame of coverage differed between media type. In addition to the Chi-square statistic, Cramer's V also was calculated to assess the strength of the relationships. Effect size standards for Cramer's V differ depending on the degrees of freedom needed for analyses (Zaiontz, n.d.).

Results indicated that there was a significant, large effect in both the civil rights/equality and other dominant frames with $\chi^{2}(3,286)=24.530, \mathrm{p}<.001$, Cramer's $\mathrm{v}=.293 .^{2}$ These results suggest that broadcast news outlets use civil rights/equality framing less frequently than print sources. Results also suggest that the other frame was used sparingly by broadcast sources indicating that this medium rarely deviates from the three main frames of coverage when talking about same-sex marriage and its legalization.

\footnotetext{
${ }^{2}$ Cramer's V effect-size standards for three degrees of freedom, as in the dominant frame by medium
} analysis, are: small (.06), medium (.17), and large (.29). 
Table 5: Dominant Frame of Coverage by Medium

\begin{tabular}{|l|l|l|l|}
\hline Dominant Frame & $\begin{array}{l}\text { Print } \\
\%(\text { count) }\end{array}$ & $\begin{array}{l}\text { Broadcast } \\
\% \text { (count) }\end{array}$ & $\begin{array}{l}\text { Total } \\
\% \text { (count) }\end{array}$ \\
\hline Religion/Morality & $13.3 \%$ & $19.9 \%$ & $16.4 \%$ \\
& $(20)$ & $(27)$ & $(47)$ \\
\hline Political/Legal & $54.0 \%$ & $69.9 \%$ & $61.5 \%$ \\
& $(81)$ & $(95)$ & $(176)$ \\
\hline Civil Rights/Equality $^{\text {a }}$ & $23.3 \%$ & $10.3 \%$ a & $17.1 \%$ \\
& $(35)$ & $(14)$ & $49)$ \\
\hline Other $^{\text {a }}$ & $9.3 \%$ a & $0 \%$ & $4.9 \%$ \\
& $(14)$ & $(0)$ & $14)$ \\
\hline Total & $100 \%$ & $100 \%$ & $100 \%$ \\
& $(150)$ & $(136)$ & $(286)$ \\
\hline
\end{tabular}

$\chi^{2}(3,286)=24.530, \mathrm{p}<.001$, Cramer's v $=.293$,

a Standardized Residuals $> \pm 2$, which indicates these frames account for the significant differences.

\section{RQ3(b) Amount of coverage by medium}

An independent-samples t-test was conducted to answer part B of research

question 3 concerning the amount of coverage between medium. Of the 286 cases, 150 of those cases were print newspaper articles and 136 were broadcast transcripts. Findings indicate that there was a significant difference in the number of words for print $(M=$ 868.5, $\mathrm{SD}=400.9)$ and the number of words for broadcast $(\mathrm{M}=4464.6, \mathrm{SD}=2916.4)$

media; $\mathrm{t}(284)=-14.95, \mathrm{p}<.001$. These results suggest that the broadcast sources analyzed in the current study discussed the issue of same-sex marriage in more depth than the print sources analyzed. It is important to note that although print articles are typically longer form than traditional broadcast news segments, 1-hour broadcast programs were included in the analysis for the current study. These longer form broadcast programs were included because they made up a large percentage of the overall broadcast sample and allowed for a more thorough and detailed report of the same-sex marriage issue. 


\section{RQ3(c) Tone of Coverage by Medium}

A chi-square analysis also was used to determine differences in the tone of coverage by medium. In order to analyze this particular part of the research question, the neutral and balanced categories were collapsed and recoded into one category to be used as the midpoint of the ordinal scale. Therefore, the new ordinal scale became 1=negative, $2=$ neutral or balanced, and $3=$ positive. The neutral and balanced stories were coded separately during the content analysis to find the count for each category; however, for the purpose of the analysis, these two coding categories were collapsed. Findings suggest that broadcast was significantly more negative than print, and print was significantly more positive than broadcast $\left(\chi^{2}(2,286)=11.589, \mathrm{p}<.01\right.$, Cramer's V $\left.=.201\right)$ with a medium effect size. ${ }^{3}$ Of the 102 negative cases, $44.9 \%$ (61) of the broadcast transcripts were negative while only $27.3 \%$ (41) of the print articles were negative. Additionally, 124 cases were coded as positive in tone with 52\% (78) print articles being coded as positive and only $33.8 \%$ (46) of broadcast transcripts being coded as positive as shown in Table 6.

Table 6: Tone of Coverage by Medium

\begin{tabular}{|l|l|l|l|}
\hline Tone & $\begin{array}{l}\text { Print } \\
\%(\text { count })\end{array}$ & $\begin{array}{l}\text { Broadcast } \\
\text { \%(count) }\end{array}$ & $\begin{array}{l}\text { Total } \\
\text { \%(count) }\end{array}$ \\
\hline Negative $^{\mathbf{a}}$ & $27.3 \%$ & $44.9 \%$ & $35.7 \%$ \\
& $(41)$ & $(61)$ & $(102)$ \\
\hline Neutral/Balanced & $20.7 \%$ & $21.3 \%$ & $21 \%$ \\
& $(31)$ & $(29)$ & $(60)$ \\
\hline Positive $^{\mathrm{a}}$ & $52.0 \%$ & $33.8 \%$ & $43.4 \%$ \\
& $(78)$ & $(46)$ & $124)$ \\
\hline Total & $100 \%$ & $100 \%$ & $100 \%$ \\
& $(150)$ & $(136)$ & $(286)$ \\
\hline
\end{tabular}

$\mathrm{N}=286, \chi^{2}(2,286)=11.589, \mathrm{p}<.01$, Cramer's $\mathrm{V}=.201$

a Standardized Residuals $> \pm 2$, which indicates these frames account for the significant differences.

3 Effect sizes for Cramer's V with two degrees of freedom are: small (.07), medium (.21), and large (.35). 
H1: News stories covering the legalization of same-sex marriage using a political/legal frame will be more negative in tone than stories using a civil rights/equality frame.

To examine hypothesis 1, the political/legal and civil rights/equality dominant frames were examined using the three-level tone variable created earlier in the analysis. As shown in Table 7, news stories using a political/legal frame were significantly more negative, exhibiting a large effect size, than stories with a civil rights/equality frame ( $\chi^{2}$ $(2,225)=32.471, \mathrm{p}<.001$, Cramers V=.380), thus, hypothesis 1 was accepted. ${ }^{4}$ These results suggest that news coverage related to same-sex marriage with a political/legal dominant frame are typically negative and stories with a civil rights/equality dominant frame are typically positive in tone.

Table 7: Tone of Political/Legal Dominant Frame vs. Civil Rights/Equality Dominant Frame

\begin{tabular}{|l|l|l|l|}
\hline \hline Tone & $\begin{array}{l}\text { Political/Legal } \\
\%(\text { count })\end{array}$ & $\begin{array}{l}\text { Civil Rights/Equality } \\
\%(\text { count })\end{array}$ & $\begin{array}{l}\text { Total } \\
\%(\text { count })\end{array}$ \\
\hline Negative $^{\mathrm{a}}$ & $36.4 \%^{\mathrm{a}}$ & $4.1 \%$ & $29.3 \%$ \\
$(64)$ & $(2)$ & $12.2 \%$ & $22.2 \%$ \\
\hline Neutral/Balanced & $25.0 \%$ & $(6)$ & $\begin{array}{l}(50) \\
\end{array}$ \\
& $(44)$ & $83.7 \%^{\mathrm{a}}$ & $48.4 \%$ \\
\hline Positive $^{\mathrm{a}}$ & $38.6 \%$ & $(41)$ & $109)$ \\
\hline Total & $(68)$ & $100 \%$ & $100 \%$ \\
& $100 \%$ & $(49)$ & $(225)$ \\
\hline
\end{tabular}

$\mathrm{N}=225, \chi^{2}(2,225)=32.471, \mathrm{p}<.001$, Cramers $\mathrm{V}=.380$,

a indicates standardized residual of $\geq \pm 2.0$ which indicates these frames account for the significant differences.

Note: The total $\mathrm{N}$ for this analysis is 225 , rather than 286 , because the other dominant frame choices were filtered out in order to run a direct comparison between the two variables in the hypothesis

H2a: News stories covering the legalization of same-sex marriage using a religion/morality frame will be more negative in tone than stories using a political/legal frame.

To examine hypothesis 2 (a), the religion/morality and political/legal dominant

frames were analyzed using the three-level tone variable that was previously created in a 
crosstab Chi-square test. As shown in Table 8, the results indicate that stories using a religion/morality frame were significantly more negative than those using a political/legal frame $\left(\chi^{2}(2,223)=24.748, \mathrm{p}<.001\right.$, Cramer's $\mathrm{V}=.333$,indicating a large effect size). Thus, hypothesis 2(a) was accepted. Although news stories about same-sex marriage that use a political/legal frame are often negative in tone, these results suggest that stories with a religion/morality frame are the most negative in tone of the three frames assessed in the current study.

Table 8: Story Tone of Religion/Morality Dominant Frame vs. Political/Legal Dominant Frame

\begin{tabular}{|l|l|l|l|}
\hline Tone & $\begin{array}{l}\text { Religion/Morality } \\
\text { \%(count) }\end{array}$ & $\begin{array}{l}\text { Political/Legal } \\
\text { \%(count) }\end{array}$ & $\begin{array}{l}\text { Total } \\
\text { \%(count) }\end{array}$ \\
\hline Negative $^{\mathrm{a}}$ & $76.6 \%^{\mathrm{a}}$ & $36.4 \%$ & $44.8 \%$ \\
& $(36)$ & $(64)$ & $(100)$ \\
\hline Neutral/Balanced & $12.8 \%$ & $25 \%$ & $22.4 \%$ \\
& $(6)$ & $(44)$ & $(50)$ \\
\hline Positive $^{\mathrm{a}}$ & $10.6 \%$ & $38.6 \%^{\mathrm{a}}$ & $32.7 \%$ \\
& $(5)$ & $(68)$ & $(73)$ \\
\hline Total & $100 \%$ & $100 \%$ & $100 \%$ \\
& $(47)$ & $(176)$ & $(223)$ \\
\hline
\end{tabular}

$\mathrm{N}=223, \chi^{2}(2,223)=24.748, \mathrm{p}<.001$, Cramer's $\mathrm{V}=.333$

${ }^{\text {a }}$ Standardized residual of $\geq \pm 2.0$ which indicates these frames account for the significant differences. Note: The total $\mathrm{N}$ for this analysis is 223 , rather than 286 , because the other dominant frame choices were filtered out in order to run a direct comparison between the two variables in the hypothesis.

H2(b): News stories covering the legalization of same-sex marriage using a religion/morality frame will be more negative in tone than stories using a civil rights/equality frame.

To examine hypothesis 2(b), the religion/morality and civil rights/equality dominant frames were examined using the previously mentioned three-level tone variable in a crosstab Chi-square analysis. As shown in Table 9, this hypothesis was accepted and the results were significant with a markedly large effect size. The stories with a religion/morality dominant frame were significantly more negative than stories using a civil rights/equality dominant frame, $\chi^{2}(2,96)=58.579, \mathrm{p}<.001$, Cramer's $\mathrm{V}=.781$. 
Table 9: Story Tone of Religion/Morality Dominant frame vs. Civil Rights/Equality Dominant Frame

\begin{tabular}{|l|l|l|l|}
\hline Tone & $\begin{array}{l}\text { Religion/Morality } \\
\boldsymbol{\%}(\text { count) }\end{array}$ & $\begin{array}{l}\text { Civil Rights/Equality } \\
\text { \%(count) }\end{array}$ & $\begin{array}{l}\text { Total } \\
\text { \%(count) }\end{array}$ \\
\hline Negative $^{\mathrm{a}}$ & $76.6 \%^{\mathrm{a}}$ & $4.1 \%$ & $39.6 \%$ \\
& $(36)$ & $(2)$ & $(38)$ \\
\hline Neutral/Balanced & $12.8 \%$ & $12.2 \%$ & $12.5 \%$ \\
& $(6)$ & $(6)$ & $(12)$ \\
\hline Positive $^{\mathrm{a}}$ & $10.6 \%$ & $83.7 \%^{\mathrm{a}}$ & $47.9 \%$ \\
& $(5)$ & $(41)$ & $(46)$ \\
\hline Total & $100 \%$ & $100 \%$ & $100 \%$ \\
& $(47)$ & $(49)$ & $(96)$ \\
\hline
\end{tabular}

$\mathrm{N}=96, \chi^{2}(2,96)=58.579, \mathrm{p}<.001$, Cramer's $\mathrm{V}=.781$

a indicates standardized residual of $\geq \pm 2.0$ which indicates these frames account for the significant differences.

Note: The total $\mathrm{N}$ for this analysis is 96 , rather than 286 , because the other dominant frame choices were filtered out in order to run a direct comparison between the two variables in the hypothesis.

H3: Issue specific or episodic framing will be used more often in news stories leading up to the time of the U.S. Supreme Court decision than after the decision.

To examine the third hypothesis, a crosstab Chi-square test was used to analyze the use of episodic and thematic framing before and after the U.S. Supreme Court decision to legalize same-sex marriage.

As shown in Table 10, the results of the analysis indicated that there was virtually no difference between the amount of stories using an episodic frame before or after. Before the decision, $93.9 \%$ (154) of the total 164 articles coded about same-sex marriage used an episodic frame and 93.4\% (114) of the total 122 articles coded after the decision also used an episodic frame. In addition, out of the complete 286 newspaper article and broadcast transcript sample, only $6.3 \%$ (18) of the stories were coded as using a thematic frame. The results of this analysis were insignificant $\left(\mathrm{N}=286, \chi^{2}(1,286)=.025, \mathrm{p}=.874\right.$, Cramer's $\mathrm{V}=.009)$. Thus, the third hypothesis was rejected. 
Table 10: Use of Episodic vs. Thematic Framing Before and After the U.S Supreme Court Decision

\begin{tabular}{|l|l|l|}
\hline Story Frame & $\begin{array}{l}\text { Before Decision } \\
\text { \% (count) }\end{array}$ & $\begin{array}{l}\text { After Decision } \\
\text { \% (count) }\end{array}$ \\
\hline Episodic & $93.9 \%$ & $93.4 \%$ \\
& $(154)$ & $(114)$ \\
\hline Thematic & $6.1 \%$ & $6.6 \%$ \\
& $(10)$ & $(8)$ \\
\hline Total & $100 \%$ & $100 \%$ \\
& $(164)$ & $(122)$ \\
\hline
\end{tabular}

Total N: 286

$\mathrm{N}=286, \chi^{2}(1,286)=.025, \mathrm{p}=.874$, Cramer's V $=.009$

H4: News stories after the Supreme Court decision will be more balanced/neutral than those before the decision.

To examine the fourth and final hypothesis in the current study, the three-tone variable for tone was used to determine whether news stories with a balanced or neutral tone were more common in the time period after the decision than in the time period before the decision. A Chi-square test was used to analyze the data for this hypothesis. The Chi-square analysis indicated there was not a significant increase in the number of balanced and neutral articles after the U.S. Supreme Court decision to legalize same-sex marriage $\left(\mathrm{N}=286, \chi^{2}(2,286)=.588, \mathrm{p}=.745\right.$, Cramer's $\left.\mathrm{V}=.045\right)$. In fact, there was a slightly larger, but non-significant, percentage of balanced and neutral articles before the decision $22.6 \%$ (37) than after the decision $18.9 \%$ (23) as shown in Table 11. Thus, hypothesis 4 was rejected. These results suggest that the because there was not an increase in the number of balanced or neutral articles after the decision, articles with a positive and/or negative tone were still being published. This continuation of the use of positive and negative tones when covering same-sex marriage may be due to the controversy surrounding this issue. 
Table 11: Stories with Neutral/Balanced Framing Before and After the U.S. Supreme Court Decision

\begin{tabular}{|l|l|l|l|}
\hline Tone & $\begin{array}{l}\text { Before Decision } \\
\text { \%(count) }\end{array}$ & $\begin{array}{l}\text { After Decision } \\
\text { \%(count) }\end{array}$ & $\begin{array}{l}\text { Total } \\
\text { \%(count) }\end{array}$ \\
\hline Negative & $34.8 \%$ & $36.9 \%$ & $35.7 \%$ \\
& $(57)$ & $(45)$ & $(102)$ \\
\hline Neutral/Balanced & $22.6 \%$ & $18.9 \%$ & $21.0 \%$ \\
& $(37)$ & $(23)$ & $(60)$ \\
\hline Positive & $42.7 \%$ & $44.3 \%$ & $43.4 \%$ \\
& $(70)$ & $(54)$ & $(124)$ \\
\hline Total & $100 \%$ & $100 \%$ & $100 \%$ \\
& $(164)$ & $(122)$ & $(286)$ \\
\hline
\end{tabular}

$\mathrm{N}=286, \chi^{2}(2,286)=.588, \mathrm{p}=.745$, Cramer's $\mathrm{V}=.045$ 


\section{CHAPTER 5: DISCUSSION}

This study used a content analysis of newspaper articles and broadcast transcripts $(n=268)$ and secondary survey data from Pew Research Center before $(n=1,889)$ and after $(\mathrm{n}=1,850)$ the decision to legalize same-sex marriage to explore the framing and agendasetting effects of news coverage during this time period. The results from the content analysis demonstrated that the three main frames that have been used to cover same-sex marriage (1) political/legal, (2) religion/morality, and (3) civil rights/equality throughout the more than 40-year debate continue to be the most common frames used in both broadcast and print sources. Additionally, the findings indicated that the variables of interest in the current study (tone, amount of coverage, frame, and dominant frame) also were different depending on the medium. These differences in frame and tone are important to consider when examining the issue of same-sex marriage from a consumer's point of view and from the media's perspective.

\section{Framing}

Of the three main frames observed in the current study, the most common frame was the political/legal frame. According to Sherkat, Powell-Williams, Maddox, and de Vries (2011), homosexuality became a major political topic after the anti-gay crusades in the 1970 s and 80 s. Since that time, the political and legal debates surrounding this topic have shown no sign of slowing down. The changing marriage laws over time in several U.S. states and the 2004 Presidential election are just two of the major political influencers that have propelled this issue into the spotlight and onto the house and senate floors in previous years. The widespread use of the political/legal frame before the decision was noted by the researcher in several articles related to potential 2016 
Presidential candidates. Coverage before the legalization using a political/legal frame also focused on the fast-approaching Supreme Court decision as a whole. Even after the decision to legalize same-sex marriage, politics still played an important role in news related to the issue. This can be attributed to the resistance by several states to adopt the law set forth by the Supreme Court. In news coverage after the decision, many of the articles using the political/legal frame highlighted the opposition of several statesKentucky, Colorado, Louisiana, Mississippi, and Texas - just to name a few. Opponents justified their disagreement of the decision as a violation of the democratic process. In fact, even Chief Justice John Roberts mentioned the issue of states' rights in his dissent. "Five lawyers have closed the debate and enacted their own vision of marriage as a matter of constitutional law,” (Resnick, Fox, \& Volz, 2015).

As a result, the large number of articles and transcripts with a political/legal frame may be attributed to this opposition by certain states and their local government officials after the decision and the discussion about the legalization before the landmark case. This finding is not unlike the 2005 study by Boyle and Schmierback which found that $40 \%$ of the stories used a political reason or action frame surrounding a 2003 U.S. Supreme Court ruling about gay sex as a form of discrimination.

The second most common news frame used to cover same-sex marriage in the current study was the religion/morality frame. With previous studies that focused on the framing of same-sex marriage mentioning the importance and prevalence of religion surrounding this issue (Lee \& Hicks, 2011; Olson, Cadge, \& Harrison, 2006; Baunach, 2011; Liebler, Schwartz, \& Harper, 2009), a continued presence of this frame in news coverage surrounding the legalization of same-sex marriage was anticipated by the 
researcher. The stories that used the religion/morality frame most often were related to the Boy Scouts decision to allow homosexual troop leaders, Kim Davis' refusal to issue same-sex marriage licenses because of her religion, and the pope's opinion of same-sex marriage.

The Boy Scouts of America organization is founded upon religious principles and also receives funding from the Church of Jesus Christ of Latter-day Saints. As a result, stories related to the Boy Scouts decision to allow gay leaders used a religion/morality frame and often included quotes from religious leaders within the church of Latter-day Saints.

Stories using a religion/morality frame in the current content analysis study highlighted the controversy of Kim Davis and her refusal to sign same-sex marriage licenses, even after the Supreme Court ruled in favor of such unions. Although the majority of news stories about Kim Davis were published in the month of September after her arrest, several articles were published in July and August and talked about the protests that took place outside of her office in Kentucky. All of the articles previously stated were published during the months that were included in the content analysis as a result of current events. Thus, these current events with a religious aspect may have influenced the amount of articles with a religion/morality frame.

Finally, Pope Francis also paid a visit to the United States in September 2015 after the Supreme Court decision to legalize same-sex marriage. In several of the articles examined in the content analysis, many were about the pope's upcoming visit to the United States and how several gay Catholics in the United States hoped to secure his 
approval of their decision to legally marry. Other stories surrounding the pope's opinion on the issue focused on Francis' disapproval of Obama allowing this legalization.

The third most common frame was the civil rights/equality frame. Although the legalization of same-sex marriage can be recognized as an issue of civil rights, the majority of stories coded before and after the decision did not utilize this frame. This limited use of the civil rights/equality frame may be attributed to the Supreme Court decision and the announcement of some 2016 Presidential candidates occurring simultaneously. Several of the articles coded asked prospective Presidential nominees for their opinions on the issue of same-sex marriage or talked about how this issue may influence certain political parties. As a result, these articles focused less on the civil rights/equality aspect and more on the political/legal aspect of the issue.

The dominant frames in the current study were analyzed over time to better understand how the frames of coverage used in stories concerning same-sex marriage changed before and after the U.S. Supreme Court decision. Results suggested that stories with a political/legal frame were used more frequently in the time period before the decision and stories with a civil rights/equality frame were more prevalent after the decision. An explanation for this change in dominant frame usage may be attributed to the political nature of the legalization of same-sex marriage. Before the decision, much of the discussion about same-sex marriage was based around its potential legalization by the Supreme Court. In addition, several articles and transcripts that were examined in the current study interviewed political candidates in an effort to understand their personal stance on the issue. However, on June 26, 2015, when the U.S. Supreme Court announced a 5-4 decision in favor of same-sex marriage, the legality of the issue was no 
longer in question. The increase in the civil rights/equality frame after the decision may also be attributed to the official legalization of same-sex marriage. This legalization led to celebration by the LGBT community and same-sex marriage supporters throughout the country. The news coverage after the decision reflected the use of the civil/rights equality frame as many of the stories coded touched on the gay pride parades throughout the country, support from key figures like Barack Obama, and news of same-sex couples rushing to nearby court houses to make their unions official. Overall, the use of these three main frames gives structure to the stories about same-sex marriage. This is important for consumers because it allows them to understand the issue of the legalization of same-sex marriage from three different sides.

\section{Public Opinion}

Secondary survey data was used to better understand the public opinion of same sex marriage surrounding the decision. This data was collected from the Pew Research Center and included responses to one survey question asked at two different points in time (May and July 2015). When analyzing survey data from the Pew Polls and the tone of coverage, the percentage of articles with a positive tone and those who favored samesex marriage matched up very closely. Thus, one may argue that agenda-setting effects may have played a role in opinions of same-sex marriage before and after the decision.

\section{Differences Between Media}

In the majority of previous research related to framing of same-sex marriage, only one medium has been analyzed. There are very few research studies based around framing of this issue that analyze both print news articles and broadcast transcripts. Therefore, in an effort to expand the current literature, newspaper articles and broadcast 
transcripts were examined in the content analysis. The four newspapers included in the analysis were The New York Times, The Washington Post, The Denver Post and USA Today. The six broadcast stations analyzed were CNN, CBS, ABC, FOX, NBC, and MSNBC. The results indicated that frame, amount of coverage, and the tone of coverage varied between media type.

There was a significant difference in the civil rights/equality and other dominant frames between print and broadcast. Both the civil rights/equality and other dominant frames were used more in print than broadcast sources, according to the results from the content analysis. In addition, the amount of coverage between print and broadcast also was significantly different. Broadcast transcripts related to the legalization of same-sex marriage had significantly more words than print coverage surrounding the decision. Although print articles are typically a longer form medium, 1-hour broadcast programs were included in the analysis because they made up a large percentage of the overall broadcast sample and allowed for a more thorough and detailed report of the same-sex marriage issue. Because these 1-hour style broadcast shows were included, the mean number of words for the broadcast medium was significantly larger than print.

The tone of same-sex marriage coverage differed between print and broadcast outlets as well. The results indicated that broadcast stories were significantly more negative than print stories about same-sex marriage surrounding the Supreme Court decision, and that the inverse was also supported. This finding is important in terms of the influence of news media. According to the Pew Research Center, $60 \%$ of Baby Boomers get their political news from television (Mitchell, Gottfried \& Matsa, 2015). Therefore, if this particular audience and other audiences are getting their news about the 
legalization of same-sex marriage primarily from television broadcasts, they may be exposed to negative coverage more frequently. In turn, this can influence the opinion of these viewers when exposed to negative coverage of same-sex marriage again and again.

\section{Tone of story frames}

\section{Religion/Morality \& Tone}

Of the three main frames examined (political/legal, religion morality, and civil rights/equality), the current study predicted that stories with a religion/morality frame would be the most negative in tone. According to Pan, Meng, and Zhou (2010), stories with a religion/morality frame often mentioned opposition to same-sex marriage because of its ability to take away from the traditional definition of marriage between a man and a woman. This argument is consistent with the stories coded in the current study with a religion/morality frame and the results supported the prediction that religion/morality framing would be the most negative frame. One interesting discovery made by the researcher was the presence of religion/morality frame articles with a positive tone and positive comments toward same-sex marriage. Several of these articles mentioned homosexual Catholics seeking approval from Pope Francis during his visit to the U.S., support from Boy Scout troop leaders open to the idea of homosexual members and leaders, and churches in the United States open to the idea of allowing gays and lesbians to marry. According to Olson, Cadge, and Harrison (2006) support or tolerance of samesex marriage and homosexuality may differ depending on one's religious denomination. They found that being a member of "any religion other than evangelical Protestantism increased one's likelihood of supporting gay-marriage" (p. 353). These changing attitudes 
from religious supporters suggest a growing tolerance from groups that traditionally opposed the idea of same-sex marriage.

\section{Political/Legality \& Tone}

The political/legal frame of coverage was predicted to be the second-most negative in tone, sandwiched between religion/morality and civil rights/equality on a scale from opposition to support. Several previous content analysis studies have noted the general negative orientation of news coverage related to same-sex marriage with a political focus (Boyle \& Schmierbach, 2005; Sherkat et al., 2011; Warren \& Bloch, 2014). The results of the current study were consistent with previous research studies as the political/legal frame was accepted as the second-most negative frame behind religion/morality. In the 286-article sample analyzed, the researcher noted several news stories with a political/legal frame that had a negative tone. The majority of these negative articles asked politicians and other public figures for their opinions of same-sex marriage, while other stories were related to the opposition of the Supreme Court's decision by certain state and local governments.

A 2015 Gallup Poll found that support for same-sex marriage among political parties reached an all-time high with $76 \%$ of Democrats in favor its legalization (McCarthy, 2015). The findings from this secondary survey data were not unlike the news stories analyzed in the current research study. Several news stories with a political/legal frame in the current study mentioned the support for same-sex marriage by several Democratic Presidential candidates such as Hillary Clinton and Bernie Sanders. In addition, the strong support from President Barack Obama after the Supreme Court's decision to legalize same-sex marriage made its way into several articles and transcripts after the 
decision. The Commander-in-Chief was quoted saying that the gay marriage ruling was a "victory for America" and that the decision made our union "a little more perfect." This increased support from key political figures may also relate to the changing views of the American public over time. In the future as increased political support continues, acceptance of same-sex marriage from those who follow those politicians may also increase. Politicians also often make guest appearances on broadcast news shows and serve as experts in print articles. Thus, if they provide positive comments about same-sex marriage in the news, the coverage will be more positively framed overall.

\section{Civil Rights/Equality \& Tone}

Of the three main story frames, the civil rights/equality frame was predicted to be the most positive of all. Pan, Meng and Zhou (2010), among others, have noted stories that talk about same-sex marriage as an issue of equality are positive in tone. These previous studies support the findings of the current study as stories with a civil rights/equality frame were significantly more positive than stories with a religion morality frame and stories with a political/legal frame. Support for marriage equality has also increased steadily over time as demonstrated by Sherkat, Powell-Williams, Maddox, and de Vries (2011) study. Their findings suggested that over the 20-year period from 1988-2008, approval of same-sex marriage increased dramatically. Currently, Gallup Poll information indicates that American support for same-sex marriage is at an all-time-high of $60 \%$ (McCarthy, 2015). This record support is also demonstrated in a time where the President of the United Sates openly applauded the decision and by consumer brands like Ben and Jerry's, which renamed its chocolate chip cookie dough ice cream to I Dough, I Dough for the summer after the U.S. Supreme Court decision was announced. As more 
Americans and popular brands become supporters of same-sex marriage, news outlets also report on this increasing support and tend to use a positive tone in the reporting. As a result, news coverage focusing on civil rights and equality uses a positive tone more often than stories that do not use this frame.

\section{Episodic vs. Thematic Framing}

Hypothesis 3 in the current study examined the use of episodic and thematic framing to see if episodic framing was more prevalent in the time period leading up to the decision. De Vreese, Peter, and Semetko (2001) found in their content analysis that news coverage surrounding the launch of the Euro used more episodic framing before the launch than after. The current study found that episodic framing was used throughout the five-month time period surrounding the U.S. Supreme Court decision to legalize samesex marriage. Due to the nature of episodic framing (framing surrounding a specific event) as opposed to thematic framing (framing of a topic in broader, more general terms), it is easy to see why episodic framing was used in the majority of news coverage surrounding the legalization of same-sex marriage. The introduction of the Euro was something that likely did not spark as many debates like the legalization of same-sex marriage, which may have attributed to less frequent use of an episodic frame after that particular event.

The passage of marriage equality was such a landmark decision and monumental occurrence, that coverage did not die off-like in de Vreese, Peter, and Semetko's study — and was still based around this event. In addition, there were several events that took place nationally after the decision that were discussed by the media. The Kim Davis controversy, one-on-one interviews with politicians about the decision, and fights for 
religious freedom laws that many believed would allow discrimination against homosexuals all dominated news coverage and meant that this issue was not quite over. Because several issues and events took place in the United States as a result of the decision, news coverage after the decision also followed these events. Therefore, news coverage of same-sex marriage still used an episodic frame after the decision because of the related events still taking place in several different states.

\section{Balanced and Neutral Coverage}

Li and Liu's (2010) content analysis study examined news coverage of same-sex marriage surrounding a political/legal issue in San Francisco - the mayor's decision to issue marriage licenses to same-sex couples. They found that coverage of the issue was more fair and balanced after the event when compared to coverage before the event. The current study formed the fourth hypothesis with expectations of discovering similar increases in balanced/neutral articles after the U.S. Supreme Court decision to legalize same-sex marriage.

Contrary to Li and Liu's findings, the current study saw no significant increase in the amount of balanced or neutral articles in the time period after the decision. In fact, the number of balanced/neutral articles was virtually the same before and after the decision. The unwavering difference in balanced/neutral articles could be attributed to the controversy of this topic and the impact of this landmark decision. Those who were in favor of same-sex marriage were celebrating the decision after the announcement of its legalization, while those who opposed the decision made their disagreement clear by boycotting the new law and even refusing to issue marriage licenses in certain states. In 
turn, these types of events after the decision are likely to have influenced the topic and tone of coverage with positive or negative aspects.

In addition, the researcher noted the unofficial stance taken by some media outlets after the decision on social media. Huffington Post and Buzzfeed changed their Twitter icons to colorful rainbows in support of the legalization. One Twitter user took a snapshot of the news organizations that boasted this support and tweeted, "This is not something news organizations do, is it?" (Johnson, 2015). This positive support from news organizations may also have impacted the low number of balanced/neutral articles after the decision. With unofficial stances taken by news outlets and organizations, balanced and neutral coverage surrounding this controversial issue is less likely. Media have the power to frame stories any way that they like and therefore, this may result more news coverage on one side or the other of the debate. Audiences should keep this in mind when gathering information from news sources, especially if they only watch the same broadcast news channels or read the same newspapers again and again.

\section{Expansion of Framing and Agenda-Setting Theories}

The theory of framing has been described by Entman (2007) as the process of selecting certain elements of "perceived reality and assembling a narrative that highlights connections among them to promote a particular interpretation," (p. 164). The current study supports this theory by examining certain frames or elements of same-sex marriage (political/legal, civil rights/equality, and religion/morality) that have been identified by previous researchers as the main frames surrounding this issue. The current study found that the majority of articles and broadcast transcripts analyzed fell into one of these three main frame categories both before and after the U.S. Supreme Court decision to analyze 
same-sex marriage. The current study expanded the research related to this topic by analyzing news coverage of same-sex marriage before and after the landmark Supreme Court case. Prior to the current study, no other research study had yet examined news coverage of this controversial legalization.

Additionally, the majority of previous research related to the framing of same-sex marriage analyzed print articles only. There were only a couple of research studies that analyzed broadcast coverage of this issue, and none of the previous research studies surrounding same-sex marriage looked at both mediums. Therefore, the current research study's analysis of both newspaper articles and broadcast transcripts expanded the literature surrounding this topic.

The theory of agenda setting was advanced in the current study by examining public opinion surrounding the legalization of same-sex marriage. Previous research has examined agenda-setting effects of same-sex marriage in different local markets (Hester \& Gibson, 2007), however, agenda-setting effects had not yet been tested in the time period surrounding the U.S. Supreme Court decision. Despite not being able to directly correlate public opinion to the tone of same-sex marriage during the five-month period analyzed in this study, results suggested that there could be some agenda-setting effects as the tone of coverage matched up closely with support for legalization.

\section{Strengths \& Limitations}

Although previous research has explored the perceptions and opinions of samesex marriage throughout the years, there was little to no research on the opinions of samesex marriage after the Supreme Court's decision to legalize it before the current study. In addition, previous research had explored the frames and tone of coverage used by media 
when covering stories related to same-sex marriage; however, no research study had explored the difference in tone of coverage before or after this major decision. Thus, this expansion of the current literature is a major strength of the current study. Another strength of the current study is the validity of measures that were used. All of the variables that were used in the current study have been modeled from previous, reputable studies that have contributed to the current knowledge base. Even after the U.S. Supreme Court decision to legalize same-sex marriage there was much controversy and discussion in the media and in the lives of many Americans. From the Kim Davis controversy to the arguments between political leaders and state government officials about states' rights, this landmark decision continues to be a topic of debate even after its legalization. The passion from supporters and opponents of this decision demonstrates the importance of the current study and the relevance of same-sex marriage as a social issue for the last four decades.

A limitation of the current study was the timeliness of the U.S. Supreme Court's decision in comparison to when the study began. Because the ruling was made shortly before the study was set to begin, there was a lack of previous research based on a landmark decision like the legalization of same-sex marriage. In addition, finding an ample amount of secondary survey data was a limitation, as there was little information related to the Supreme Court decision in the form of Gallup Polls or Pew survey research after the decision. In fact, one of the research questions had to be omitted from the study because of the lack of information and data sets from Gallup. The Lexis Nexis Academic database also presented several limitations throughout this study. There were several news outlets that were not available on the database including the Wall Street Journal, 
and therefore, transcripts and articles could not be used from those sources. Additionally, even with the use of filters and other methods of eliminating irrelevant data, several articles that mentioned same-sex marriage only briefly made their way into the initial sample. Once these unrelated articles and transcripts were eliminated by the student coders, the sample size left for analysis was much smaller than originally anticipated. Inter-coder reliability also proved to be a limitation of the current study as the Episodic vs. Thematic framing and the other framing category resulted in low Scott's pi values. Despite the high percent agreement between coders for these categories, this limitation must still be taken into consideration when interpreting the results of the study. Finally, the researcher could not use primary survey data to test agenda setting effects. This lack of primary research proved to be a limitation when comparing public opinion to the secondary survey data that was used. Survey data collected by the researcher would have allowed for deeper analysis; however, this data would have needed to be collected before and after the decision (June 26, 2015).

Finally, omitting coverage surrounding same-sex marriage in the third month after the decision (September 2015) is also a limitation of this study. Eliminating these articles about Kim Davis could be seen as a limitation because she was a part of the news agenda and the story being told. However, these stories were not coded because the news surrounding her arrest became more about her and her personal religious beliefs rather than the same-sex marriage legalization decision. 


\section{Future Research}

To expand the current research even further, there are several different approaches that could be taken. Although the current study examined broadcast stories, the transcripts varied greatly within the sample. Some of the transcripts analyzed were from nightly news segments while others were from 1-hour type shows. As a result, the information included in the two types of transcripts was very different. Future studies may want to explore the differences in coverage between these types of broadcast shows to determine whether the frames used and tone of coverage vary. Another interesting approach that could be taken in future studies surrounding this issue would be to see if tone and frame of coverage between each broadcast and print outlet corresponds with the political ideologies of viewers.

For example, does FOX present the issue of same-sex marriage in a negative light more often than other outlets, and if so, do those who watch FOX more often also have a negative view of the issue? Using a content analysis and primary research methods, these questions could be answered. Future research may also examine the tone of social media posts related to same-sex marriage and the information within those posts differ from traditional news media. As previously stated, several news outlets demonstrated support for the U.S. Supreme Court decision to legalize same-sex marriage with tweets and hashtags like \#LoveWins. Social media platforms may serve as an outlet for news organizations to express support or opposition to controversial topics. Thus, comparing social media posts to traditional print and broadcast media would provide interesting information related to the differences in reporting style. 


\section{Practical Implications}

What does this all mean in terms of media and the reader? A previous study by Lee and Hicks (2011) found there was a connection between media consumption and attitudes toward same-sex marriage. Both framing and agenda setting theories suggest that media have an impact on the way consumers or readers process information and form opinions about a particular issue. As society grows to become more accepting of homosexuality and same-sex marriage, it is easy to see how the media play an important role in the portrayal of this issue.

Today, there are more positive representations of the LGBTQ community in media than ever before. Television shows like "Glee," "Orange is the New Black", and "Transparent" are all examples of positive representations of homosexuality and transgender issues. In addition, the announcement of Caitlyn Jenner's transition from well-known Olympic athlete to Vanity Fair cover model also received a lot of media attention. By understanding the impact that media have on society, consumers can educate themselves on the issues at hand and navigate the print and broadcast landscape more effectively. 


\section{References}

Baker, P. (2013, March 25). Bill Clinton's Decision, and Regret, on Defense of Marriage Act. The New York Times. http:www.newyorktimes.com

Baunach, D. M. (2011). Decomposing trends in attitudes toward gay marriage, 19882006. Social Science Quarterly (Wiley-Blackwell), 92(2), 346-363.

Boyle, M., \& Schmierbach, M. (2005). Measuring media coverage of same-sex marriage International Communication Association. Retrieved from

http://search.ebscohost.com/login.aspx?direct=true\&db=ufh\&AN=18655458\&site $=$ ehost-live

Brewer, P. (2003). The shifting foundations of public opinion about gay rights. The Journal of Politics, 65(4), 1208-1220

Camaj, L. \& Weaver, D. (2013). Need for orientation and attribute agenda setting during a U.S. election campaign. International Journal of Communication, 7, 1442-1463

Colistra, R. (2010). The rumble and the dark: Regional newspaper framing of the Buffalo Mine Creek Disaster of 1972. Journal of Appalachian Studies, 16(1), 79-100

De Vreese, C. H., Peter, J., \& Semetko, H. A. (2001). Framing politics at the launch of the euro: A cross-national comparative study of frames in the news. Political Communication, 18(2), 107-122. doi:10.1080/105846001750322934

Distaso, M. \& Bortree, D. (2014). Ethical Practice of Social Media in Public Relations. New York, NY: Routledge.

Entman, R. (2007). Framing Bias: Media in the distribution of power. Journal of Communication, 57, 163-173.

Gamson, J. (2000). Lesbians, gays, straights, and the media. GLQ: A Journal of Lesbian \& Gay Studies, 6, 451-454.

Goffman, E. (1974) Frame Analysis: An essay on the organization of experience. North Eastern University Press

Hackl, A., Boyer, C., \& Galupo, M. (2013). From 'gay marriage controversy' (2004) to 'endorsement of same-sex marriage' (2012): Framing bisexuality in the marriage equality discourse. Sexuality \& Culture, 17(3), 512-524.

Hester, J. B., \& Gibson, R. (2007). The agenda-setting function of national versus local media: A time-series analysis for the issue of same-sex marriage. Mass Communication \& Society, 10(3), 299-317. 
Iyengar, S. (1990). Framing responsibility for political issues: the case of poverty. Political Behavior, 12(1), 19-40.

Johnson, M. (2015, June 26). 34 tweets responding to the legalization of gay marriage. The Daily Signal. http://www.dailysignal.com

Johnson, T. (2012). Equality, morality, and the impact of media framing: Explaining opposition to same-sex marriage and civil unions. Politics \& Policy, 40(6), 10531080. doi:10.1111/j.1747-1346.2012.00398.x

Jowett, A. \& Peel, E. (2010). “Seismic Cultural Change?”:British media representations of same-sex marriage. Womens International Forum, 33, 206-214

Joyce, M. (2013). Picking the best intercoder reliability statistic for your digital activism content analysis. Digital activism research project. http://digital-activism.org

Kirka, D. (1990, March 6). UCI students renew demands: policies: protestors denounce the chancellor's negative response to previous demands that gays be given access to family housing. The Los Angeles Times. http://www.articles.latimes.com

Lee, T. \& Hicks, G. (2011). An analysis of factors affecting attitudes toward same-sex marriage: Do the media matter? Journal of Homosexuality, 58(10), 1391-1408.

Li, X., \& Liu, X. (2010). Framing and coverage of same-sex marriage in U.S. newspapers. Howard Journal of Communications, 21(1), 72-91. DOI: $10.1080 / 10646170903501161$

Liebler, C. M., Schwartz, J., \& Harper, T. (2009). Queer tales of morality: The press, same-sex marriage, and hegemonic framing. Journal of Communication, 59(4), $653-675$.

McCarthy, J. (2015). Record high 60\% of Americans support same-sex marriage. Gallup. http://www.gallup.com

McCombs, M. (2005). A look at agenda setting: past, present, and future. Journalism Studies, 6(4), 543-557.

McCombs, M. \& Reynolds, A. (2002). News influence on our pictures of the world. In J. Bryant \& D. Zillmann (Eds.) Media effects: Advances in theory and research. 118.

McCombs, M. \& Shaw, D. (1974). The agenda setting function of mass media. Public Opinion Quarterly, 36(2), 176-187.

McKeever, B. (2012). News framing of autism: understanding media advocacy and the combating autism act. Science Communication, 35(2), 213-240. 
Mitchell, Gottfried, \& Matsa (2015, June 1). Social Media-the local TV for the next generation? The Pew Research Center. http://www.journalism.org

Nakamura, D. (2015, June 26). Obama on same-sex marriage ruling: "We have made our union a little more perfect." The Washington Post.

http://www.washingtonpost.com

Nardi, P. (1996, February 20). The endless debate on gay union. The Baltimore Sun. http://www.articles.baltimoresun.com

Olson, L., Cadge, W. \& Harrison, J. (2006). Religion and public opinion of same-sex marriage. Social Science Quarterly, 87(2), 340-360.

Pew Research Center, Washington, D.C. (n.d). Content analysis: Human coding of news media. http://www.pewresearch.org/methodology/about-content-analysis/humancoding-of-news-media/

Reese, S. D. (1991). Setting the media's agenda: A power balance perspective. In J.A. Anderson (Ed.), Communication Yearbook, 309-340.

Resnick, B., Fox, L., \& Volz, D. (2015, June 26). Why four justices were against the Supreme Court's huge gay marriage decision. The Atlantic. Retrieved from http://www.theatlantic.com.

Riffe, D. (1993). The effectiveness of random consecutive day and constructed week sampling in newspaper content analysis. Journalism \& Mass Communication Quarterly. 70(1). 133-139.

Saad, L. (2013, July 8). TV is American's main source of news. Gallup. http://www.gallup.com

Sherkat, D., Powell-Williams, M., Maddox, G., de Vries, K. (2011). Religion, politics, and support for same-sex marriage in the United States, 1988-2008. Social Science Research, 40, 167-180.

Scheufele, D. \& Tewksbury, D. (2007)Framing, agenda setting, and priming: the evolution of three media effects models. Journal of Communication, 21, 9-20.

Studley, A. (2013). Marriage equality: Media coverage and public opinion. Senior Hoonors Projects. Paper 317. http://digitalcommons.uri.edu/srhonorsprog/317.

Taylor, S. J. (2015, July 23). The money impact of the supreme court's gay marriage ruling: A look at how social security, taxes, and other financial matters will now affect same-sex couples. U.S. News \& World Report. http://www.money.usnews.com 
Turner, W. (1982, November 28). Couple law asked for San Francisco. The New York Times. http://www.nytimes.com

Warren, D. \& Bloch, K. (2014). Framing same-sex marriage: media constructions of California's Proposition 8. The Social Science Journal, 51, 503-513.

Whitehead, A. L. (2014). Politics, religion, attribution theory, and attitudes toward samesex unions. Social Science Quarterly (Wiley-Blackwell), 95(3), 701-718. doi:10.1111/ssqu. 12085

Winter, J. \& Eyal, C. (1981). Agenda setting for the civil rights issue. The Public Opinion Quarterly, 45(3), 376-383.

Wolf, R. (2014, November 7). Gay marriage bans in four states upheld, Supreme Court review likely. USA Today. http://www.usatoday.com

Zaiontz, C. (n.d). Effect size for Chi-square test. Real Statistics. http://www.realstatistics.com.

Zorthian, J. (2015, June 26). These are the states where SCOTUS just legalized same-sex marriage. Time Magazine. http://www.time.com 


\section{Appendix A: Story Analysis Form Instructions}

Fill out one form per story. Below, you will find definitions and examples to help you select the appropriate category.

Coder:

Initials of coder

\section{Date:}

Enter the date that the article ran using a two-digit, month-date-year format. For example, if you were coding a story that ran on January 23, 2004, you would enter 012304.

\section{Newspaper Name:}

Write down the name of the newspaper in which the news story was featured.

\section{Broadcast Outlet:}

Television only. Enter the name of the broadcast outlet/show that ran the story.

\section{Length of Article/Story:}

Enter the length of the story being coded. If it is a newspaper article, write down the number of paragraphs and the number of words provided by the digital archive. If coding a broadcast transcript, enter the length of the story in seconds.

\section{Headline:}

Enter the headline verbatim from the article or transcript.

\section{Time of Coverage:}

Please review the following categories before you begin coding. Make sure you refer to these categories throughout the coding process.

Time 1: Before the U.S. Supreme Court Decision: Choose this if the story was published or broadcasted seven months before the U.S. Supreme Court decision to legalize same-sex marriage. These dates range from November 25, 2014-June 25, 2015.

Time 2: After the U.S. Supreme Court Decision: Choose this if the story was published or broadcasted seven months after the U.S. Supreme Court decision to legalize same-sex marriage. These dates range from June 26, 2015-January 26, 2016. 


\section{Tone of Coverage}

Please review the following categories before you begin coding. Make sure you refer to these categories throughout the coding process. Do not code the paragraphs based on your own opinion of Postive, Neutral or Balanced, or Negative.

1. Negative: Choose this category if the story contained negative statements or quotes. For example, mark this category if the story contained words or phrases that indicate a sense of disapproval or disregard, accusations or unflattering comments, or words or phrases that portrayed same-sex marriage in a negative light. Some negative words include, but are not limited to, the following: bad, weakening the institution of marriage, cause for concern, threatening or damaging for children or society, negative effects/consequences. Only choose this category if the story contained all or mostly negative remarks, comments, statements, or quotes regarding any discussion surrounding same-sex marriage and/or the legalization of same-sex marriage.

2. Neutral: Choose this category if there was no indication of either a positive or negative tone. That is, if the story contained only factual remarks, comments, statements, or quotes. A story falling into this category is presented as simply reporting on this issue rather than showing any blatant indication of positive or negative tone.

3. Balanced: Choose this category if the story contained an equal number of both positive and negative statements related to same-sex marriage.

4. Positive: Choose this if the story contained statements or quotes that suggest praise, approval, optimism, flattery, or any angle that portrayed same-sex marriage in a good light. Some positive indicators include, but are not limited to, the following: amazing, incredible, good, fair, equal, right(s), deserve, better, positive, strengthen, benefits, acceptance, advocate, victory, win/winning, free, proud. Only choose this category if the story contained all or mostly positive remarks, statements, comments, or quotes regarding any discussion surrounding same-sex marriage and/or the legalization of samesex marriage. 


\section{Instructions for Coding Tone}

\section{Remember, you are assessing the entire story, not paragraph by paragraph.}

First: Make sure you are familiar with the above categories, and refer to them frequently when trying to determine whether the story contains any indication of a particular tone. The tone category sheet should be kept by you at all times.

Second: Read the story. Remember, at first you will only be identifying whether the story contains any positive or negative statements, remarks, comments, or quotes. As you read through the story, highlight any negative remarks, statements, comments or quotes in ORANGE. Highlight any positive statements in BLUE. Remember, news stories typically present just the facts without indicating any type of tone. Therefore, you may only have a few positives and/or negatives in a story. Again, make sure you use only the definitions listed above. If you are having trouble deciding whether a particular comment is positive or negative, try to put yourself in the place of the average reader. Ask yourself, if I were just a regular person reading this story, would I think this comment was negative or positive?

Third: When you are finished reading the story and highlighting any positive or negative comments with the appropriate color, add them up and determine whether the story was Positive, Balanced OR Neutral, or Negative, and check the appropriate tone category.

Remember:

- If the story only contained factual information or straight news reporting, and if it contained no positive or negative comments, you should code it as Neutral.

- If the story contained an equal number of positive AND negative comments you should code it as Balanced.

- If the story contained all or mostly positive comments, you should code it as Positive.

- If the story contained all or mostly negative comments, you should code it as Negative.

- If the story contained positive AND negative comments but not an equal number, you should subtract the smaller number from the larger number and code the story using the result. For example, if a story contained five (5) positive comments and three (3) negative comments, you would subtract three from five and come up with two positive statements. Therefore, you would code the story as Positive. 


\section{Frame of Coverage}

Please review each frame before coding. You MUST refer to these categories throughout the coding process. Do not code the story based on your opinion of what you think the frame means. Code each story based on one of the following frames. Note: There may be more than one frame used in each story.

1. Religion/Morality Frame: This frame includes stories that cast opposition to gay rights and same-sex marriage in support for traditional moral values and religious beliefs or attitudes. These stories often include arguments against same-sex marriage based on the "sacred institution of marriage" and may also mention social norms and the heteronormative definition of marriage being between and man and a woman. In addition, religious sources/figures are often used for quotes and comments included in stories with this frame.

2. Political Frame: This frame often includes stories that cast opposition to same-sex marriage based on political views or political party support/stance. Views of elected officials or political nominees currently running for office are often included. News stories with a political frame also often include events related to public policy, including but not limited to, the following: the issuing of same-sex marriage licenses, constitutional bans, and the passage of new laws related to gay rights and/or same-sex marriage. In addition, political frames also focus on the difference between party support of same-sex marriage (traditional opposition of Republican/GOP and the recent backing/support by liberal or democratic figures). In addition, political figures and sources are often used for quotes and comments in stories with this frame.

3. Civil Rights/Equality Frame: This frame often includes stories that demonstrate support for same-sex marriage and gay rights based on "equal rights" and egalitarianism. This frame positions same-sex marriage as a civil rights, human rights, or acceptance issue. Stories with this frame may focus on constitutional rights or legal issues and often include statements from gay activists and supporters. In addition, this frame may also include stories that focus on the rights of the LGBTQ community as a whole in relation to same-sex marriage.

4. Other: Choose this category if the story does not fit into any of the others categories listed above. This category should be used sparingly. Most stories should fit into one of the other frames. If this category is chosen, make sure you mark the appropriate frames with a check or $\mathbf{X}$ on the lines provided. 


\section{Frame of Coverage Instructions}

Keep both sheets out at all times during the coding process - even if you think you have the coding categories memorized. Refer to the sheets throughout the coding. Remember, you are assessing each paragraph for frame and the entire story for the dominant frame.

\section{First: Frame}

Select the frames that are used in the news article or transcript. Mark all that apply.

\section{Second: Dominant Frame}

Determine the most dominant frame of the story. To do so, please refer to the frames and definitions provided. You should not determine the dominant frame by assigning each paragraph a frame. Instead, you should ask yourself - what is the main premise of the story? What is it really about? What sticks out the most in this story?

If you are having trouble, use the headline and lead paragraph to help you determine the most dominant frame.

\section{Example:}

A story about the county clerk in Kentucky, Kim Davis refusing to issue same-sex marriage licenses to a gay couple because of her religion can be seen as using a political frame or a religious frame. In this case, you should select the religion/morality frame because although the issuing of the marriage license is a matter of public policy, her refusal to issue these license for religious reasons is the main focus of the story. The fact that she is holds a public office is important but should not lead you to code the frame as political/legal.

\section{Episodic and Thematic Frame}

Please review the following two story frames before coding. You MUST refer to these categories throughout the coding process. Code the entire story based on one of the following frames.

1. Episodic Frame: This story frame is based on whether or not the story is focused around a specific event and often depicts public issues in terms of concrete instances.

2. Thematic Frame: This story frame is based on a more general story topic and places the issue in a broader context. 


\section{Appendix B:}

\section{Newspaper Story Analysis Form}

\section{Coder}

Newspaper

Date

\section{Headline}

Length of article (write the \# of paragraphs)

Word Count

Time of Coverage 1.(Before decision)

2.(After decision)

Tone of Coverage 1.(Negative)

2.(Neutral)

3.(Balanced)

4.(Positive)

Frames Used (Choose all that apply)

Religion/Morality

Civil Rights/Equality

Political/legal

Other (List Below)

Episodic or Thematic Frame 1. (Episodic)

2. (Thematic)

Dominant Frame (Choose one)

Religion/Morality

Civil Rights/Equality

Political/legal

Other (List Below)

Quotes/Notes 


\section{Appendix C:}

\section{Broadcast Story Analysis Form}

Coder

Broadcast Outlet

Date

Show

\section{Headline}

Length of story (\# of words)

SSM section (\# of pages)

Time of Coverage 1.(Before decision)

2.(After decision)

Tone of Coverage 1.(Negative)

2.(Neutral)

3. Balanced)

4.(Positive)

Frames Used (Choose all that apply)

Religion/Morality

Civil Rights/Equality

Political/legal

Other (List Below)

\section{Episodic or Thematic Frame}

1.(Episodic)

2.(Thematic)

Dominant Frame (Choose one)

Religion/Morality Civil Rights/Equality

Political/legal Other (List Below)

\section{Quotes/Notes}

